\title{
Pleural effusion: diagnosis, treatment, and management
}

This article was published in the following Dove Press journal:

Open Access Emergency Medicine

22 June 2012

Number of times this article has been viewed

\section{Vinaya S Karkhanis \\ Jyotsna M Joshi}

Department of Respiratory Medicine, TN Medical College and BYL Nair Hospital, Mumbai, India
Correspondence: Jyotsna M Joshi Department of Respiratory Medicine, TN Medical College and BYL Nair Hospital, Mumbai 400008, India Tel +22 2308 I490

Email drjoshijm@email.com
Abstract: A pleural effusion is an excessive accumulation of fluid in the pleural space. It can pose a diagnostic dilemma to the treating physician because it may be related to disorders of the lung or pleura, or to a systemic disorder. Patients most commonly present with dyspnea, initially on exertion, predominantly dry cough, and pleuritic chest pain. To treat pleural effusion appropriately, it is important to determine its etiology. However, the etiology of pleural effusion remains unclear in nearly $20 \%$ of cases. Thoracocentesis should be performed for new and unexplained pleural effusions. Laboratory testing helps to distinguish pleural fluid transudate from an exudate. The diagnostic evaluation of pleural effusion includes chemical and microbiological studies, as well as cytological analysis, which can provide further information about the etiology of the disease process. Immunohistochemistry provides increased diagnostic accuracy. Transudative effusions are usually managed by treating the underlying medical disorder. However, a large, refractory pleural effusion, whether a transudate or exudate, must be drained to provide symptomatic relief. Management of exudative effusion depends on the underlying etiology of the effusion. Malignant effusions are usually drained to palliate symptoms and may require pleurodesis to prevent recurrence. Pleural biopsy is recommended for evaluation and exclusion of various etiologies, such as tuberculosis or malignant disease. Percutaneous closed pleural biopsy is easiest to perform, the least expensive, with minimal complications, and should be used routinely. Empyemas need to be treated with appropriate antibiotics and intercostal drainage. Surgery may be needed in selected cases where drainage procedure fails to produce improvement or to restore lung function and for closure of bronchopleural fistula.

Keywords: thoracocentesis, biopsy, thoracoscopy, decortication

\section{Introduction}

A pleural effusion, ie, an excessive accumulation of fluid in the pleural space, indicates an imbalance between pleural fluid formation and removal. Accumulation of pleural fluid is not a specific disease, but rather a reflection of underlying pathology. Pleural effusions accompany a wide variety of disorders of the lung, pleura, and systemic disorders. Therefore, a patient with pleural effusion may present not only to a pulmonologist but to a general internist, rheumatologist, gastroenterologist, nephrologist, or surgeon. To treat pleural effusion appropriately, it is important to determine its cause. With knowledge of the pleural fluid cytology, biochemistry, and clinical presentation, an etiological diagnosis can be established in approximately $75 \%$ of patients. ${ }^{1}$ Common causes of pleural effusion are shown in Figure 1. In up to $20 \%$ of cases, the cause remains unknown despite a diagnostic workup. submit your manuscript $\mid$ www.dovepress.com

Dovepress

http://dx.doi.org// 0.2/47/OAEM.S29942
Open Access Emergency Medicine 2012:4 31-52 


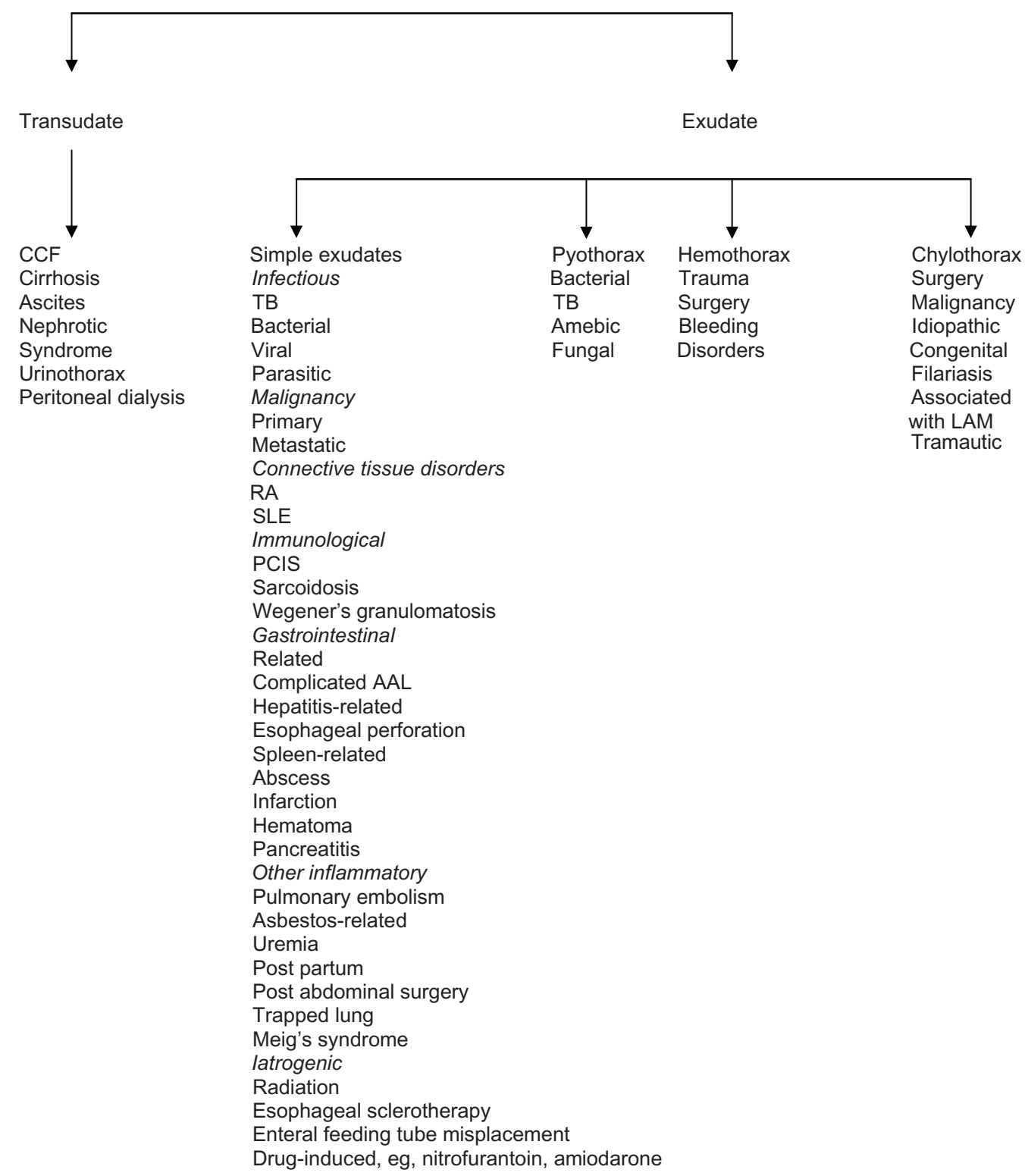

Figure I Causes of pleural effusion.

Abbreviations: AAL, amebic abscess of liver; CCF, congestive cardiac failure; LAM, lymphangioleomyomatosis; PCIS, post cardiac injury syndrome; RA, rheumatoid arthritis; SLE, systemic lupus erythematosus; TB, tuberculosis.

\section{Diagnosis}

The clinical presentation of pleural effusion depends on the amount of fluid present and the underlying cause. Many patients have no symptoms at the time a pleural effusion is discovered. Possible symptoms include pleuritic chest pain, dyspnea, and a dry, nonproductive cough. The chest pain associated with pleural effusion is caused by pleural inflammation of the parietal pleura resulting from movement-related friction between the two pleural surfaces. ${ }^{2}$ Pleuritic chest pain may be localized or referred. The pain is usually sharp and is exacerbated by movement of the pleural surfaces, as with deep inspiration, coughing, and sneezing. The pain eases with strapping of the chest or on accumulation of fluid. Because dyspnea and chest pain are nonspecific symptoms, a careful history and physical examination are important in narrowing the differential diagnosis. The approach to a patient with pleural effusion is shown in Figure 2.

\section{History}

History provides information about the possible etiology of pleural effusion and guidelines for necessary investigations. A history of pneumonia suggests parapneumonic effusion, either complicated (empyema or empyema-like) or uncomplicated. Fever indicates an infective etiology. 
History/clinical examination/x-ray chest posteroanterior/lateral decubitus/lateral

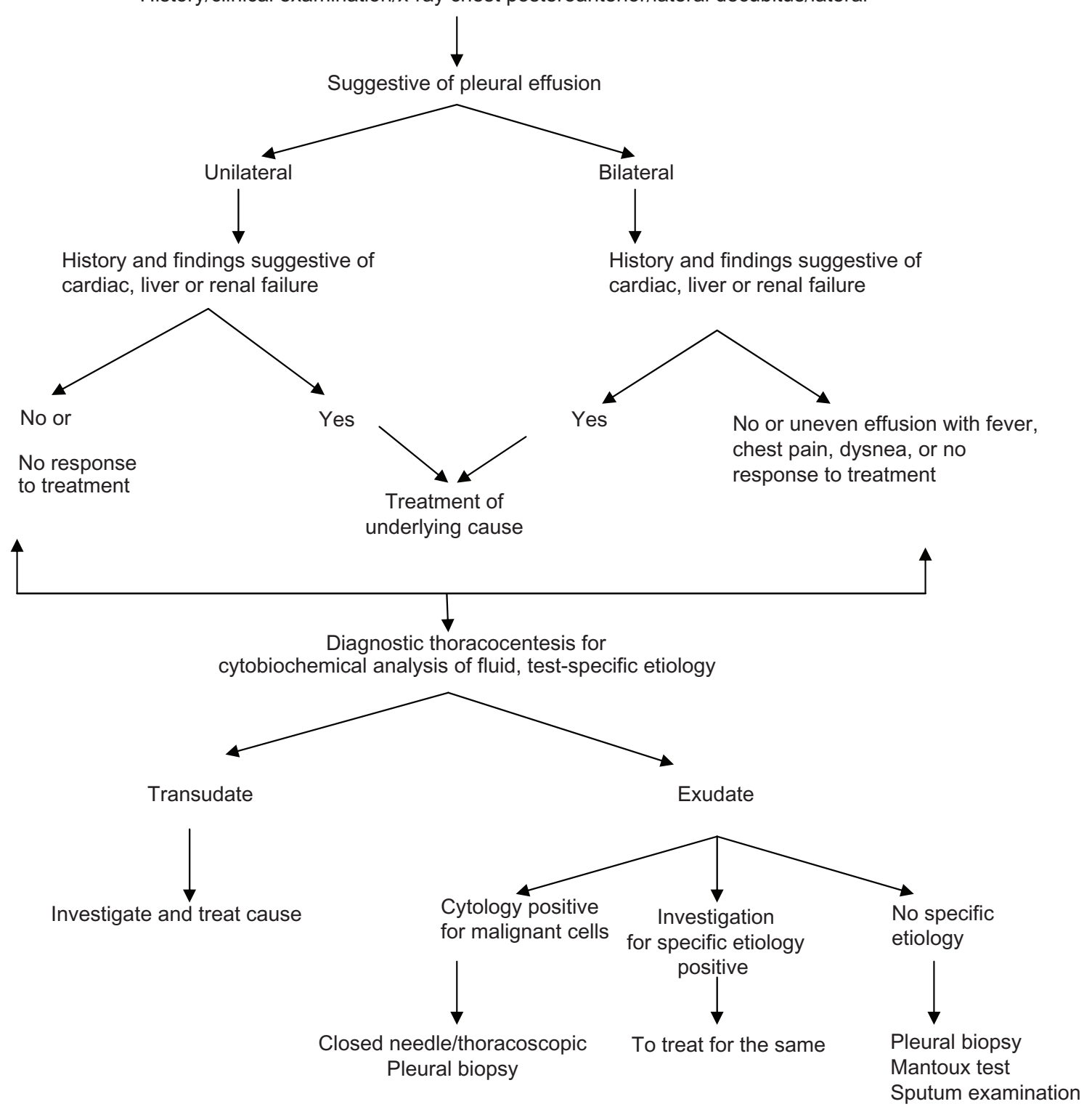

Figure 2 Approach to a patient with pleural effusion.

A history of cardiac, renal, or liver impairment can suggest transudative effusion. Older age, weight loss, and a history of smoking point towards a diagnosis of malignant pleural effusion. Recent leg swelling or deep vein thrombosis may result in an effusion related to pulmonary embolism. Trauma may result in hemothorax or chylothorax. Previous exposure to asbestos may be the cause of benign or malignant effusion related to mesothelioma. Recent esophageal procedures or history of alcohol binging suggest pleural effusion related to esophageal rupture. Physical findings such as ascites may indicate cirrhosis, ovarian cancer, or Meigs syndrome. ${ }^{3}$ Postcardiac injury syndrome should be considered in cases of fever, dyspnea, and pleuritic chest pain up to 3 weeks following cardiac surgery. ${ }^{4}$ Unilateral leg swelling can strongly indicate pulmonary embolism, and bilateral leg swelling is associated with transudates, such as those caused by heart or liver failure. A pericardial friction rub occurs in pericarditis. History and findings suggestive of connective tissue disease, and certain long-term medications, including amiodarone, 5 methotrexate, phenytoin, nitrofurantoin, and isoniazid, ${ }^{6}$ suggests that as a possible etiology. $^{7}$

\section{Physical examination}

Physical findings are signs of volume gain, reduced tactile vocal fremitus, dullness on percussion, shifting dullness, and 
diminished or absent breath sounds. Shifting dullness will be absent with massive and loculated effusions. Massive pleural effusions present with respiratory embarrassment and signs of mediastinal shift. Other findings may be related to associated systemic disease.

\section{Imaging studies Chest X-ray}

Standard posteroanterior and lateral chest radiography remains the most important technique for initial diagnosis of pleural effusion. The amount of fluid to be evident on a posteroanterior film is $200 \mathrm{~mL}$, whereas costophrenic angle blunting can be appreciated on a lateral film when approximately $50 \mathrm{~mL}$ of fluid has accumulated. Classically, a homogenous opacity is seen with obliteration of the costophrenic angle and a curved upper border, ie, the Ellis S-shaped curve (Figure 3 ). This is a radiological illusion and occurs as a medial radiological density due to the presence of partially aerated lung between the anterior and posterior fluid layers, whereas laterally the density is higher due to the presence of fluid only. The actual fluid level is horizontal. Atypical radiological findings are due to loculated effusion, which could be lateral or lamellar (Figure 4), mediastinal, apical, subpulmonic, or fissural. Fissural loculations (Figure 5A and B) are biconvex opacities, mimic tumor tissue, are most commonly seen in congestive heart failure, and disappear after treatment. Resolving pleural effusions sometimes give rise to a rounded opacity due to peripheral atelectasis that is variable in size and usually about $3-5 \mathrm{~cm}$ in diameter.

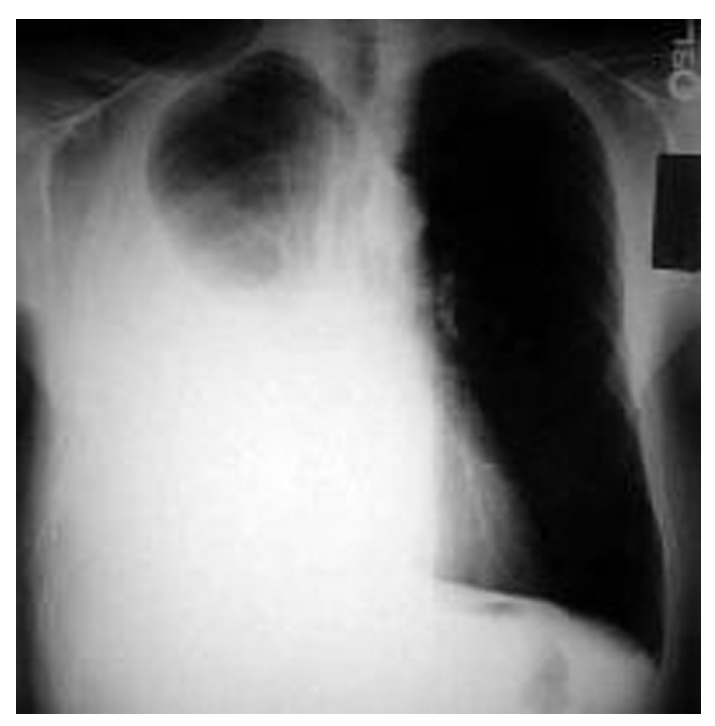

Figure 3 X-ray chest, posteroanterior view, with Ellis S-shaped curve.

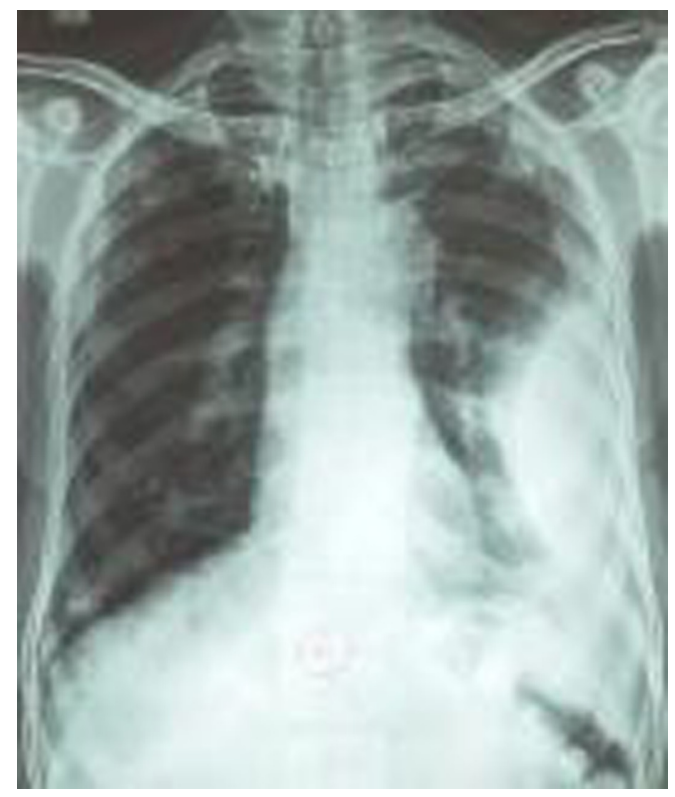

Figure $4 \mathrm{X}$-ray chest, posteroanterior view, with lamellar effusion.

It is most commonly located basally and dorsally and is composed of a swirl of atelectatic parenchyma adjacent to thickened pleura. The pathognomonic sign is the "comet tail" (Figure 6) that results from crowding of vessels and bronchi as they enter the atelectatic region. This condition is known as Blesovsky's syndrome, ${ }^{8}$ rounded atelectasis, helical atelectasis, folded lung, pleuroma, atelectatic pseudotumor, shrinking pleuritis, or pulmonary pseudotumor. It is most often noted as an asymptomatic, incidental finding on chest radiography. ${ }^{9}$ Doyle and Lawler ${ }^{10}$ have proposed seven criteria for diagnosis of rounded atelectasis, as a rounded, peripheral lung mass never completely surrounded by lung, a mass that is most dense at its periphery, a mass that forms an acute angle with the pleurae, adjacent pleural thickening, vessels and bronchi merging towards the mass, a blurred centrally directed edge, and the presence of an air bronchogram. Computed tomography can be helpful for depicting the full extent of this benign disease process and confirming the diagnosis. Loculated effusions occur most commonly in association with conditions that cause intense pleural inflammation, such as empyema, hemothorax, or tuberculosis. Radiographic clues suggestive of a subpulmonic effusion ${ }^{11,12}$ (Figure 7A) are: apparent elevation of the ipsilateral diaphragm; movement of the apex of the hemidiaphragm from the medial to lateral third; flattening of the medial aspect of the diaphragm; nonvisualization of the lower lobe blood vessels below the diaphragm; and the distance from the apparent diaphragm 

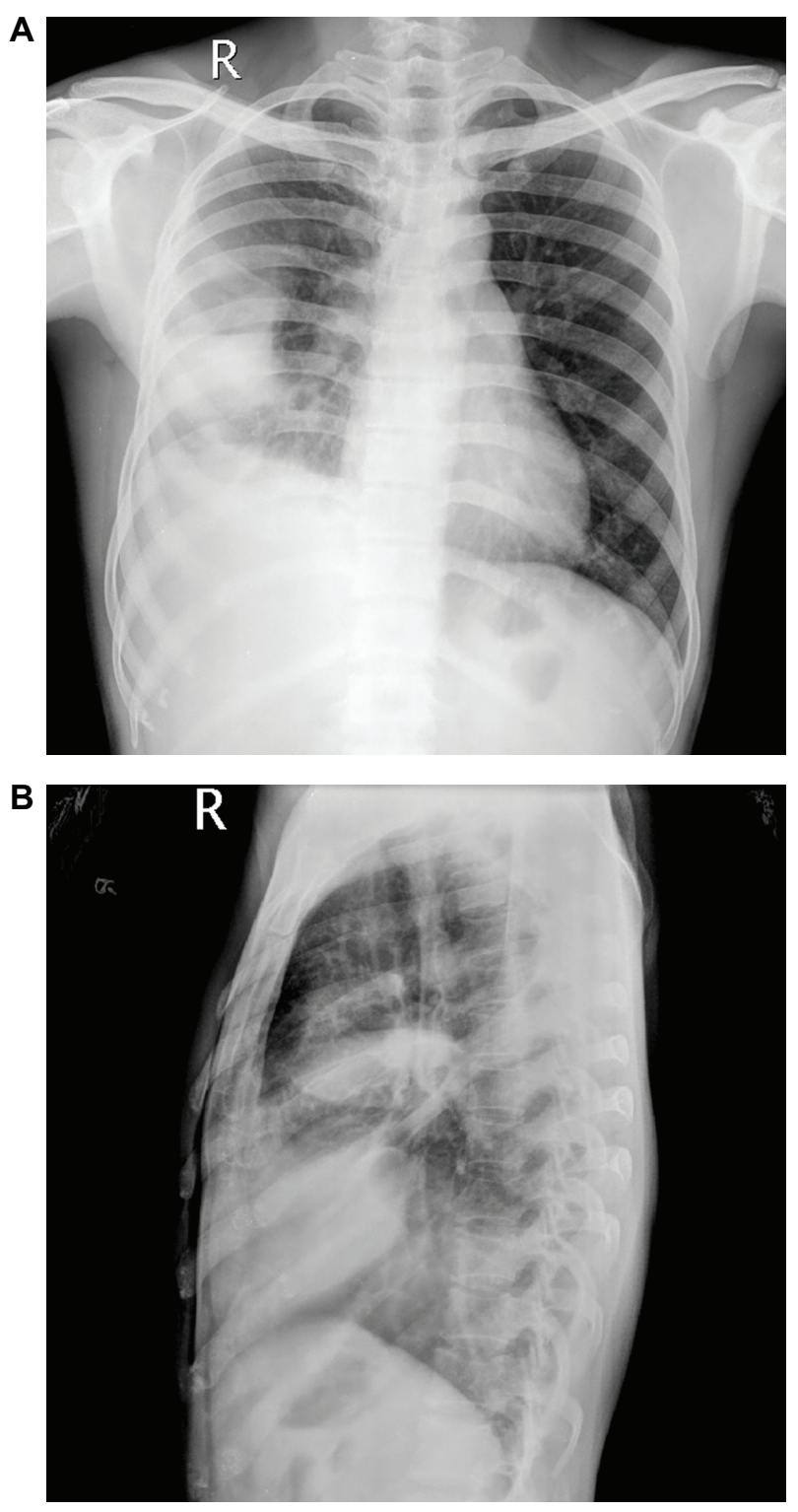

Figure 5 (A) X-ray chest, posteroanterior view, with fissural effusion, and (B) X-ray chest, lateral view, with fissural effusion.

to the fundic gas is increased on the left. Lateral decubitus radiography (Figure 7B) is extremely valuable for evaluation of a subpulmonic effusion. It is very sensitive, detecting effusions as small as $5 \mathrm{~mL}$ in experimental studies, ${ }^{13,14}$ and should be a routine test. A large or massive pleural effusion usually causes contralateral mediastinal shift (Figure 8). The most common diagnosis with a massive effusion is malignancy, other causes being complicated parapneumonic effusions and tuberculosis. ${ }^{15,16}$ Absence of contralateral mediastinal shift with an apparent large to massive effusion narrows the differential diagnosis to carcinoma of the ipsilateral main stem bronchus with atelectasis

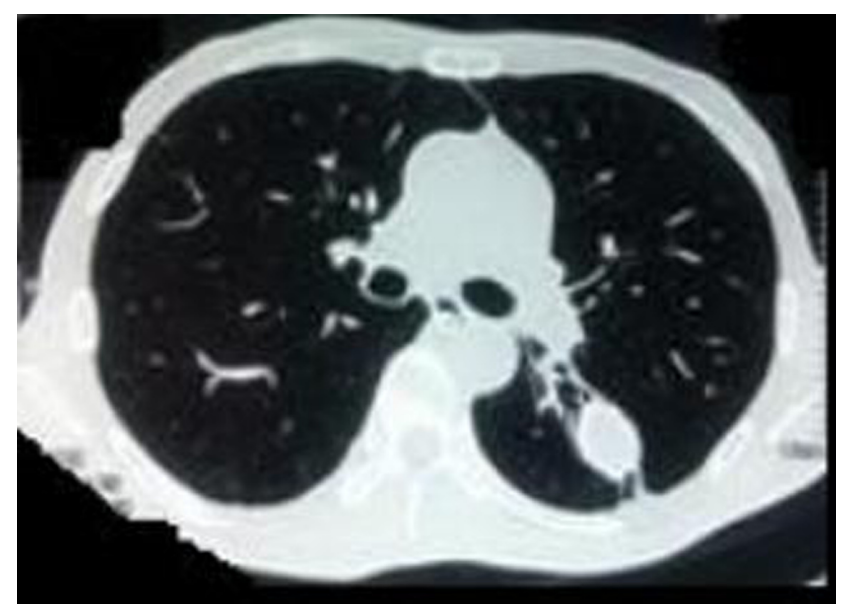

Figure 6 Computed tomography showing "comet tail" sign.

(obstructed bronchus with collapse) with or without pleural metastasis, a fixed mediastinum due to malignant lymph nodes or fibrosis, malignant mesothelioma/pleural thickening, or tumor infiltration of the ipsilateral lung. ${ }^{17}$ The presence or absence of other findings on chest radiography, in addition to the clinical presentation, may help narrow the differential diagnosis.

\section{Ultrasonography thorax}

Even small amounts of pleural effusion can be detected accurately by ultrasonography. The ultrasonographic image of pleural effusion is characterized by an echo-free space between the visceral and parietal pleura. Ultrasonography is useful in cases of loculated pleural effusion for confirmation of the diagnosis and for marking a site for thoracocentesis. In the presence of hemithorax opacification on chest radiography, ultrasonography is also helpful in distinguishing between fluid-filled and solid lesions. ${ }^{18}$ The sonographic characteristics of effusion are helpful in differentiating transudates from exudates. ${ }^{19}$ According to the internal echogenicity, effusion can be subclassified as anechoic, complex nonseptated, complex septated, or homogenously echogenic. Effusions are usually exudates when they are septated or show a complex or homogeneously echogenic pattern. Dense echogenic patterns are most often associated with hemorrhagic effusion or empyema. Pleural thickening is defined as focal echogenic lesions arising from the visceral or parietal pleura that are greater than $3 \mathrm{~mm}$ in width, with or without irregular margins. ${ }^{20}$ Pleural tumors are well defined, hypoechoic, or echogenic solid nodular lesions located in the parietal or visceral pleura. If an abnormal elevation of the hemidiaphragm is 

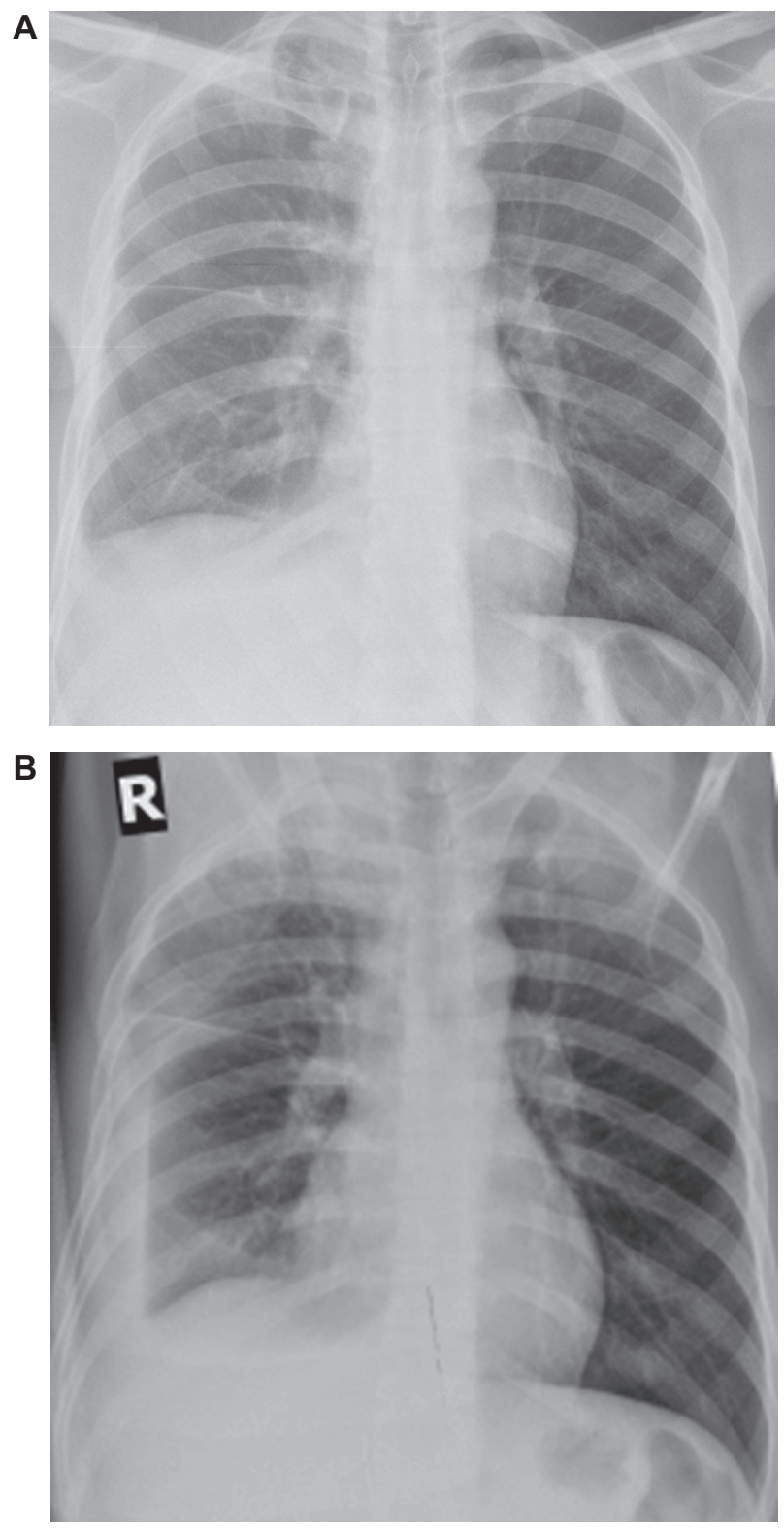

Figure 7 (A) X-ray chest, posteroanterior view with subpulmonic effusion, and (B) lateral decubitus $X$-ray showing free fluid.

noted on the chest radiograph, subpulmonic effusion can be differentiated from subphrenic fluid collection by means of ultrasonography. ${ }^{21}$

\section{CT thorax}

Computed tomography (CT) scanning with its cross-sectional images can be used to evaluate complex situations in which the anatomy cannot be fully assessed by plain radiography or ultrasonography. ${ }^{22} \mathrm{CT}$ can be useful in helping to select the site of drainage of an empyema, ${ }^{23}$ differentiating empyema from lung abscess, ${ }^{24}$ and identifying the location of the chest tube in failed empyema drainage. ${ }^{25}$ The split

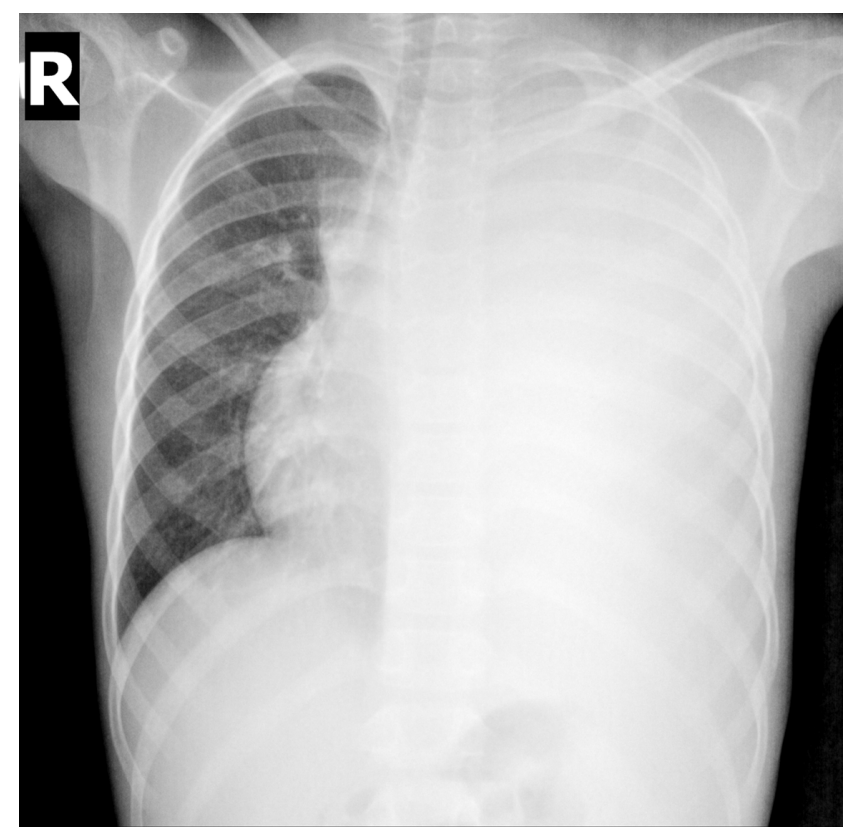

Figure $8 \mathrm{X}$-ray chest, posteroanterior view, with massive effusion and contralateral mediastinal shift.

pleura sign (Figure 9) seen on contrast-enhanced CT of the chest suggests underlying pleural thickening. There is enhancement of the thickened inner visceral and outer parietal pleura, with separation by a collection of pleural fluid. ${ }^{26}$ In a study of 74 patients, 39 of whom had malignant disease, Leung et $\mathrm{al}^{27}$ showed that malignant disease is favored by circumferential, nodular, mediastinal, and parietal pleural thickening greater than $1 \mathrm{~cm}$ (Figure 10). These features have specificities of $94 \%, 94 \%, 88 \%$, and $100 \%$, respectively, and sensitivities of $51 \%, 36 \%, 56 \%$, and $41 \%$. Along with findings related to pleural effusions, CT is helpful in identifying parenchymal lung lesions, masses, and enlarged mediastinal lymph nodes. CT angiography should be ordered if pulmonary embolism is strongly suspected.

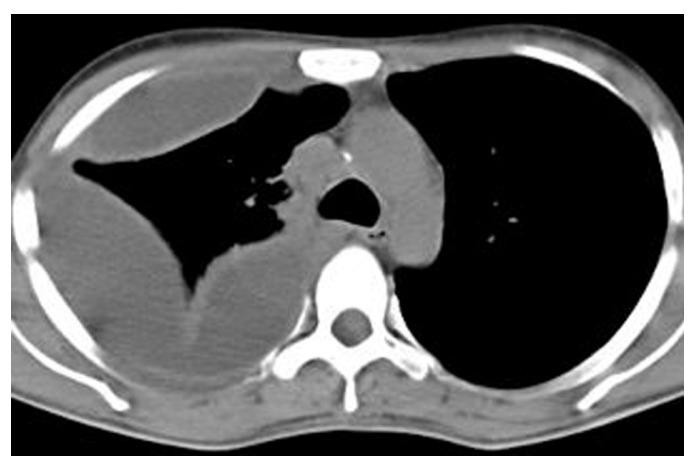

Figure 9 Contrast-enhanced computed tomography: split pleural sign. 


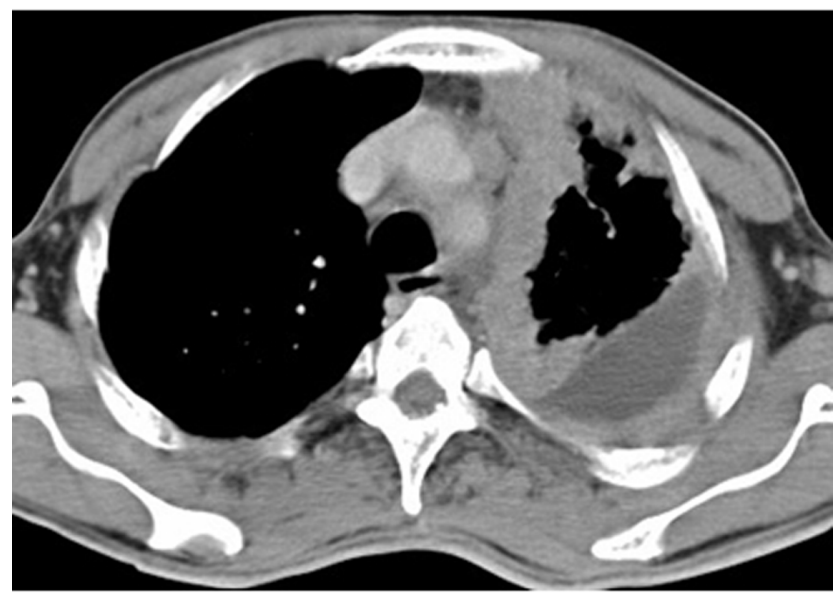

Figure 10 Contrast-enhanced computed tomography: Leung's criteria. ${ }^{80,81}$

\section{F-I 8 fluorodeoxyglucose positron emission tomography}

F-18 fluorodeoxyglucose positron emission tomography seems promising for differentiating between benign and malignant pleural diseases, with a sensitivity of $97 \%$ and a specificity of $88.5 \% .^{28,29}$ However, inflammatory processes, such as a rheumatoid effusion and tuberculosis, may also be positive. ${ }^{30,31}$

\section{Thoracocentesis and cytobiochemical fluid analysis}

Thoracocentesis should be performed in all patients with more than a minimal pleural effusion (ie, larger than $1 \mathrm{~cm}$ in height on lateral decubitus radiography, ultrasonography, or CT) of unknown origin. Aspiration should not be performed for bilateral effusions in a clinical setting strongly suggestive of a pleural transudate, unless there are atypical features or the patient fails to respond to therapy. ${ }^{32}$ Diagnostic pleural tap with biochemical, cytological, and microbiological examination of the fluid is needed for correct diagnosis (Table 1). Differentiation between transudate and exudate is crucial before further tests are undertaken. A percutaneous pleural biopsy may be necessary in a case of exudative effusion for definitive diagnosis. Color, odor, and character of the fluid are occasionally helpful in narrowing the differential diagnosis (Table 2). Hemorrhagic effusions can be differentiated from traumatic pleural taps by observing serial samples of pleural tap which clear up in the case of a traumatic pleural tap. The routine pleural fluid evaluation usually includes determination of protein, $\mathrm{pH}$, lactate dehydrogenase, glucose, and albumin levels, with adenosine deaminase levels and cell count for differential and cytological examination. ${ }^{33}$

Characterization of pleural fluid as an exudate or transudate is an important step in pleural fluid analysis. ${ }^{34}$ Light's criteria $^{35}$ (Table 3) are the most sensitive for identifying exudates, with $98 \%$ sensitivity but have lower specificity (74\%), although a study by Heffner et al failed to demonstrate any particular test or test combination with superior diagnostic accuracy ${ }^{36}$ On the basis of Light's criteria, some patients who actually have a transudative pleural effusion will be thought to have an exudative pleural effusion. If the clinical appearance suggests a transudative effusion, but the pleural fluid is an exudate according to Light's criteria, the difference between albumin levels in serum and in pleural fluid should be measured. Almost all patients with a serum albumin level $>1.2 \mathrm{~g} / \mathrm{dL}$ higher than the pleural fluid albumin level have a transudative effusion. These effusions are known as transexudative effusions. ${ }^{37}$ For example, in patients with congestive cardiac failure, diuretics move water via

Table I Diagnosis based on pleural fluid analysis

\begin{tabular}{ll}
\hline Diagnosis & Criteria \\
\hline Tuberculosis & Exudate, lymphocytic predominance, positive acid-fast bacillus smear or cultures, ADA $>50$ U/L \\
Empyema & Exudative with PMN predominance/pus, positive Gram stains or cultures, LDH $>$ I000, glucose $<40$ mg\%, pH $<7.2$ \\
Malignancy & Exudate, lymphocytic predominance, positive cytology \\
Hemothorax & Hemorrhagic, hematocrit $>50 \%$ of blood \\
Esophageal rupture & $\mathrm{pH}<7$, high salivary amylase \\
Urinothorax & $\mathrm{pH}<7$, transudate, pleural fluid-to-serum creatinine ratio $>$ I \\
Chylothorax & Triglycerides $>$ II0 mg/dL, chylomicrons, cholesterol/triglyceride ratio $<$ I \\
Rheumatoid pleurisy & Exudate, lymphocytic predominance, rheumatoid factor positive $>$ I:320, low glucose $<40$ mg\%, ADA $>50$ U/L \\
Lupus pleuritis & Exudate with PMN predominance, LE cells positive, ANA positive $>$ I:I60 \\
Pancreatitis & Exudate with PMN predominance, plenty of RBC \\
& Acute: increased serum and pleural amylase \\
Fungal infection & Chronic: increased pleural fluid amylase, serum amylase normal \\
\hline
\end{tabular}

Abbreviations: ADA, adenosine deaminase; ANA, antinuclear antibody; LDH, lactate dehydrogenase; LE, lupus erythematosus; PMN, polymorphonucleocytes; RBC, red blood cells. 
Table 2 Relationship between pleural fluid appearance and causes

\begin{tabular}{ll}
\hline Cause & Fluid appearance and odor \\
\hline Empyema & Pus \\
Anerobic empyema & Pus, putrid \\
Pseudochylothorax and chylothorax & Milky white \\
Urinothorax & $\begin{array}{l}\text { Urine } \\
\text { Amebic liver abscess }\end{array}$ \\
$\begin{array}{l}\text { Esophageal rupture } \\
\text { Trauma, pulmonary embolism, benign brown } \\
\text { asbestos-related effusion, pneumonia, } \\
\text { malignant neoplasm, after myocardial }\end{array}$ & Food particles \\
infarction, pancreatitis & \\
Hydatidothorax & \\
Bile-stained & Clear with hydatid membranes \\
\hline
\end{tabular}

diffusion from the extravascular pleural space into the blood, leading to an increase in the protein and lactate dehydrogenase concentration in pleural fluid. The serum protein concentration increases, but not as much as in pleural fluid, because the intravascular fluid is replaced from the extravascular space. Other parameters, such as cholesterol, bilirubin, lactate dehydrogenase, and alkaline phosphatase levels, can also be used. Studies ${ }^{38,39}$ comparing the accuracy of Light's criteria with cholesterol measurements, bilirubin levels, and the serum-effusion albumin gradient have shown a very high sensitivity of Light's criteria (98\%), a lower specificity ( $77 \%$ and $83 \%$ ), and an overall accuracy of almost $95 \%$. A cutoff value $>0.66$ for lactate dehydrogenase levels in pleural fluid, ie, the upper limit of the laboratory normal might be a better discriminator (ie, "modified Light's criteria"). ${ }^{40}$

A total nucleated cell count of $1000 / \mathrm{mL}$ is the cutoff value for transudates and exudates. Effusions with total cell counts lower than $1000 / \mathrm{mL}$ are transudates, whereas those with higher counts are exudates. When polymorphonuclear cells predominate, the patient has an acute process affecting the pleural surfaces. When nucleated cell counts exceed 10,000/ $\mathrm{mL}$, a diagnosis of parapneumonic effusion is likely. However, in empyema, the nucleated cell count may be extremely low, ie, less than 200 neutrophils, if the majority of the neutrophils have undergone autolysis as a result of pleural fluid acidosis and low oxygen tension. In chronic exudative effusions, nucleated cell counts are usually lower than $5000 / \mathrm{mL}$, with the

Table 3 Light's criteria ${ }^{35}$ for exudative pleural effusion

Pleural fluid protein divided by serum protein $>0.5$

Pleural fluid LDH divided by serum LDH $>0.6$

Pleural fluid LDH more than two-thirds the upper limit

of normal serum LDH

Abbreviation: $\mathrm{LDH}$, lactate dehydrogenase. most common causes being malignant and tuberculous pleural effusions. Pleural lymphocytosis is common in malignancy and tuberculosis. If there is concomitant parenchymal shadowing, the most likely diagnosis is parapneumonic effusion and pulmonary embolism with infarction.

An eosinophilic pleural effusion is defined as the presence of $10 \%$ or more eosinophils in pleural fluid. The presence of pleural fluid eosinophilia is of little use in the differential diagnosis of pleural effusions ${ }^{41}$ and is often the result of air or blood in the pleural cavity. ${ }^{42}$ However, an eosinophilic pleural effusion cannot be considered to be an indicator of benign disease and should be investigated like any other pleural effusion. ${ }^{43}$ Conditions such as parapneumonic effusions, tuberculosis, drug-induced pleurisy, benign asbestos pleural effusion, Churg-Strauss syndrome, pulmonary infarction, parasitic disease, and malignancy may all present with pleural fluid eosinophilia. ${ }^{44}$

In the normal state, the glucose concentration in pleural fluid is equivalent to the glucose concentration in peripheral blood because glucose has a low molecular weight and is transported from the blood to the pleural fluid by simple diffusion across the endothelium-mesothelium membranes. A low glucose concentration is defined as a ratio of pleural fluid glucose to serum glucose that is less than 0.5 and is found in exudative pleural effusions secondary to empyema, rheumatoid disease, lupus, tuberculosis, malignancy, or esophageal rupture. ${ }^{45}$ Increased pleural fluid amylase is seen in cases of pancreatic disease, esophageal rupture, and malignancy. Cytology of pleural fluid is diagnostic in only $60 \%$ of cases. ${ }^{46}$

\section{Percutaneous pleural biopsy}

Percutaneous pleural biopsies are of greatest value in the diagnosis of granulomatous and malignant diseases of the pleura. They are performed on patients with undiagnosed exudative effusions and nondiagnostic cytology, and when there is clinical suspicion of tuberculosis or malignancy. The biopsy specimens should be placed in $10 \%$ formaldehyde for histological examination and sterile saline for tuberculosis culture. When obtaining biopsies from focal areas of pleural nodularity shown on contrast-enhanced CT scans, image guidance should be used. Image-guided pleural biopsy is the investigation of choice in cases of malignant mesothelioma, with a sensitivity of $86 \%$ and a specificity of $100 \%{ }^{47}$ The procedure can be performed as a blind percutaneous needle biopsy or through thoracoscopy or open thoracotomy.

Closed percutaneous needle biopsy has traditionally been performed to investigate the etiology of exudative pleural 
effusion, and was first described in $1958 .{ }^{48}$ Abrams and Copes pleural biopsy needles are most commonly used for the procedure. ${ }^{49}$ At least four samples need to be taken to optimize diagnostic accuracy. ${ }^{50}$ Cowie et al, in a large study of 750 needle biopsies, reported a $90 \%$ success rate in obtaining pleural tissue. ${ }^{51}$ Complications of pleural biopsy include site pain $(1 \%-15 \%)$, pneumothorax $(3 \%-15 \%)$, vasovagal reaction $(1 \%-5 \%)$, hemothorax $(<2 \%)$, site hematoma $(<1 \%)$, and transient fever $(<1 \%)$. If a pneumothorax is caused, only $1 \%$ of cases require chest drainage. Morrone et al ${ }^{49}$ compared these two needles in a small randomized study of 24 patients, and the diagnostic yield was similar, but samples were larger with an Abrams needle although not with better diagnostic performance. A Copes needle is easy to use, less expensive, and results in fewer complications. All grades of junior medical staff can perform this procedure following suitable training. ${ }^{52}$ In view of low cost, easy availability, and very low complication rates, closed pleural biopsy is a very important diagnostic tool for physicians and should be used routinely. Closed pleural biopsy should be offered to all patients with exudative pleural effusion, and thoracoscopic procedures should be reserved for cases that remain undiagnosed. ${ }^{53}$

\section{Thoracoscopy}

Open thoracotomy, once the gold standard, has given way to less invasive video-assisted thoracoscopic surgery. Thoracoscopy should be considered when less invasive tests have failed to give a diagnosis. Harris et $a l^{54}$ studied 182 consecutive patients who underwent thoracoscopy and showed a diagnostic sensitivity of $95 \%$ for malignancy. Apart from its diagnostic use, medical thoracoscopy had also been used as a therapeutic tool in chemical pleurodesis for malignant pleural effusion ${ }^{55}$ and spontaneous pneumothorax ${ }^{56}$ repair of bronchopleural fistula, performing drainage, and lysis of loculations in pleural infections. The major contraindication with this procedure is lack of pleural space due to adhesions. Complications from medical thoracoscopy are minor and infrequent. $^{57}$

\section{Fiberoptic bronchoscopy}

Tuberculosis and malignancy are the two most common causes of an undiagnosed pleural effusion, and transbronchial biopsy may be diagnostic. LeRoux, in reviewing his experience with chest malignancies, infers that fiberoptic bronchoscopy, in the setting of a pleural effusion with another abnormality on chest radiography gives a diagnostic yield of close to $50 \%{ }^{58}$ A study by Heaton and Roberts ${ }^{59}$ concluded that routine fiberoptic bronchoscopy is not justified in the evaluation of pleural effusions.

\section{Exudative effusion Tuberculous pleural effusion}

It is important to consider the possibility of tuberculous pleuritis in all patients with an undiagnosed pleural effusion. Tuberculous pleuritis is thought to represent primarily a hypersensitivity reaction to tuberculous protein, and the bacillary burden in the pleural space is low. Patients usually present with an acute illness. The most frequent symptoms are cough, which is nonproductive and associated with chest pain, which is usually pleuritic in nature. The pain usually precedes the cough. Most patients are febrile, but approximately $15 \%$ will be afebrile. ${ }^{60}$ Dyspnea may be present if the effusion is large and related to mechanical dysfunction of the diaphragm due to inversion. Effusions are usually unilateral and can be of any size. On rare occasions, pleural tuberculosis can present with pleural-based nodules and thickening.

The fluid is serous or hemorrhagic with formation of coagulum. Pleural fluid is an exudate with proteins frequently $>5 \mathrm{~g} / \mathrm{dL}$ and lymphocytic predominance. Pleural fluid glucose may be reduced, but is usually similar to the serum level. The $\mathrm{pH}$ is usually above 7.3 , but may be reduced in some cases. The lactate dehydrogenase level in pleural fluid is usually higher than that in serum. Presence of eosinophils or mesothelial cells is unlikely. Intense lymphocytic infiltration covers both pleural surfaces and prevents the mesothelial cells from entering the pleural space. Various studies have confirmed that the pleural fluid from patients with tuberculosis rarely contains more than $5 \%$ mesothelial cells. ${ }^{61,62}$ Patients infected with human immunodeficiency virus (HIV) with tuberculous pleuritis may have mesothelial cells in their pleural fluid, a feature common with peripheral blood CD4 counts below $100 \mathrm{~mm}^{3}{ }^{63}$ Pleural fluid smears for acid-fast bacilli should be obtained in HIV-positive patients, and are positive in $10 \%-20 \%$ of effusions, ${ }^{64}$ with $20 \%-50 \%$ being positive on pleural fluid cultures. ${ }^{65}$ Pleural biopsy shows caseating granuloma. Histopathology and pleural tissue culture for acid-fast bacilli improve the diagnostic rate to about $90 \% .{ }^{66}$ Adenosine deaminase levels $>50$ IU/L support the diagnosis in high prevalence areas, but do not exclude tuberculosis from other conditions. ${ }^{67}$ Adenosine deaminase activity is found to be higher in tuberculous pleural effusions than in other exudates, ${ }^{68,69}$ overall sensitivity in the diagnosis of tuberculous pleural effusions is $99 \%$ and specificity is $93 \% .^{70}$ Adenosine deaminase isoenzymes are not measured routinely 
in India. However, these are superior to adenosine deaminase in the diagnosis of tuberculous pleuritis and can be used as a routine test in the diagnostic workup of patients with pleural effusions in areas with a high prevalence of tuberculosis. ${ }^{71}$ Adenosine deaminase may not be raised in patients with concomitant HIV infection. ${ }^{72}$ A tuberculin test may be negative initially due to compartmentalization of lymphocytes at the site of infection. More than 8 weeks after the development of symptoms, the skin test is almost always positive. The skin test may become negative in patients with immunosuppression and HIV infection. Without treatment, tuberculous pleuritis usually resolves spontaneously, but the patient frequently develops active tuberculosis at a later date.

\section{Empyema}

An empyema or empyema-like fluid occurs due to bacterial infection in the pleural space. An effusion is called an empyema when the concentration of leucocytes becomes macroscopically evident as a thick and turbid fluid, ie, pus. Light's criteria used for diagnosis of empyema are: exudate/pus with polymorphonuclear predominance; Gram stain showing organisms; low glucose; elevated lactate dehydrogenase $>1000$; and $\mathrm{pH}<7.2$. Accumulation of exudative pleural fluid associated with an ipsilateral pulmonary infection that does not look like pus but satisfies the above is called empyema-like fluid. Only $50 \%$ of empyema cases are associated with pneumonia. Adenosine deaminase is elevated and its activity in tuberculous empyema is determined by isoenzyme ADA-1. ${ }^{73}$ Etiological agents for empyema are shown in Table 4. Patients usually suffer from an acute febrile illness, anemia, and digital clubbing. Anerobic infections tend to present with a more subacute or chronic condition. ${ }^{74}$

Table 4 Etiology of empyema

\begin{tabular}{ll}
\hline Age & Etiologic agent \\
\hline Infant & Haemophilus influenzae \\
& Streptococcus pneumoniae \\
Child & Staphylococcus aureus \\
& Streptococcus pneumoniae \\
Elder & Streptococcus pneumoniae \\
& Anerobes \\
& Haemophilus influenzae \\
& Moraxella catarrhalis \\
& Streptococcus pneumoniae \\
Immunocompetent young adult & Anerobes \\
& Staphylococci \\
& Haemophilus influenzae \\
& Moraxella catarrhalis \\
& Klebsiella spp. \\
Immunocompromised young adult & Streptococcus pneumoniae \\
& Anerobes \\
\hline
\end{tabular}

Chest X-ray/CT thorax shows evidence of ipsilateral pleural effusion and pulmonary infiltrates in $50 \%$ of cases associated with pneumonia. Loculated effusions can be confirmed by lateral decubitus X-ray or ultrasonography. The American Thoracic Society delineates three progressive phases of empyema, ie, an early exudative phase, an intermediate fibrinopurulent phase, and a late organizing phase. ${ }^{75}$ If empyema is not treated adequately, pleural thickening with trapped lung, empyema necessitans, and bronchopleural fistula can develop. When pleural inflammation is intense, its resolution may be associated with deposition of a thick layer of dense fibrous tissue on the visceral pleura, a condition known as fibrothorax. As a result of marked pleural thickening, the hemithorax becomes contracted and its mobility is reduced. As it progresses, the intercostal spaces narrow and the mediastinum may be displaced ipsilaterally. Radiologically this presents as opaque minihemithorax, perhaps with calcification on the inner aspect of peel. CT scan confirms pleural thickening, seen as a "split pleura sign" on contrast-enhanced study. A bronchopleural fistula can be detected early if there is continuous air leak through an intercostal drainage tube and amphoric breathing on auscultation. The diagnosis can be confirmed by the methylene blue test (Figure 11), bronchoscopy, and CT thorax with maximum intensity projection images for demonstration of a fistula. Bronchoscopy may be useful for therapeutic closure of a proximal fistula or to ascertain the condition of the bronchi. CT thorax helps to confirm the diagnosis and in detection of a mass or foreign body in the vicinity, which may be helpful in the preoperative assessment if the patient needs closure of a bronchopleural fistula.

\section{Malignant pleural effusion}

Malignant pleural effusion can result from primary malignancies of the pleurae or with intrathoracic and extrathoracic malignancies that reach the pleural space by hematogenous, lymphatic, or contiguous spread. More than $75 \%$ of malignant pleural effusions are caused by neoplasms of the lung, breast, or ovary, or by lymphoma. ${ }^{76}$ Metastatic adenocarcinoma is the most common tumor type. ${ }^{77}$ Patients present with a nonspecific history and with cough and dyspnea. About $60 \%$ of patients with malignant pleural effusion experience a constant dull or occasionally localized pleuritic chest pain. ${ }^{78}$ It is an exudative effusion with lymphocytic predominance, and often hemorrhagic. It is defined by the presence of malignant cells in the pleural space; for which fluid needs to be sent for cytology (200 units of heparin in $20 \mathrm{~mL}$ of fluid). Standard pleural fluid cytology can provide confirmation of a malignant pleural effusion, but has a diagnostic yield of 

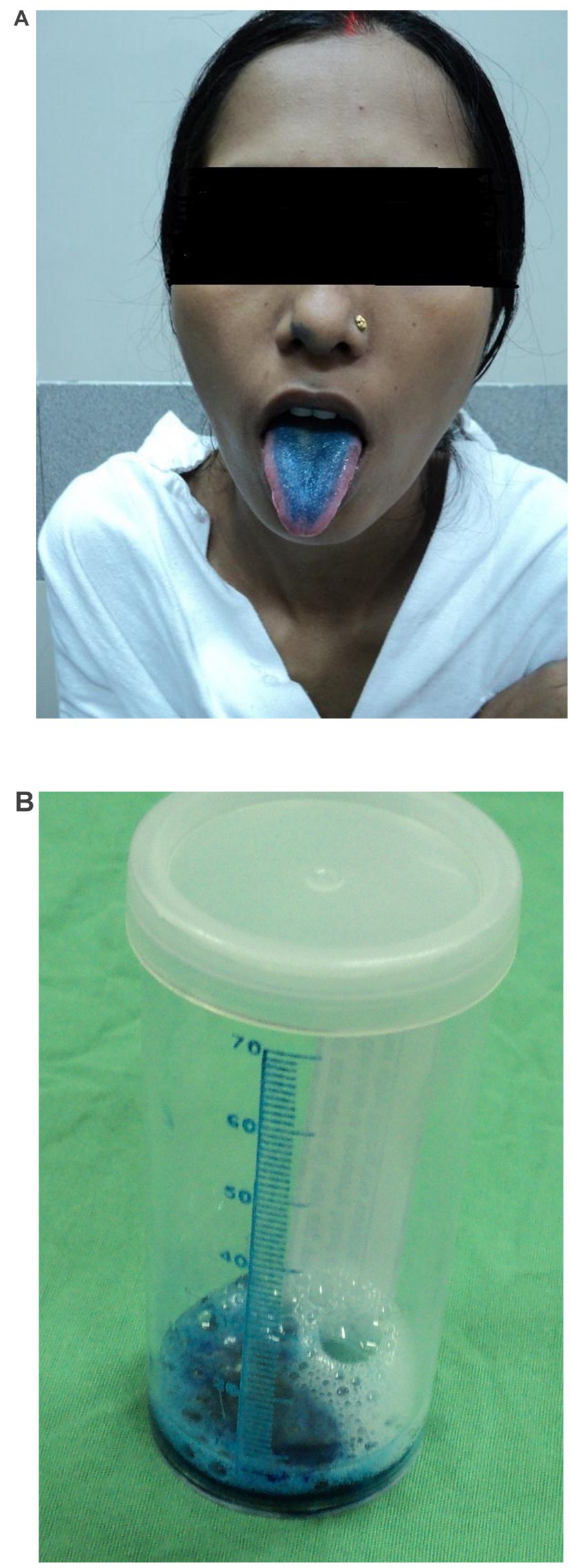

Figure I I (A) and (B) methylene blue test. only $65 \%$. Patients with cancer can develop pleural effusion as an indirect effect of cancer, even when cancer cells are absent from the pleural space. These effusions are known as paraneoplastic or paramalignant pleural effusions. They can result from mediastinal lymph node tumor infiltration, bronchial obstruction, radiochemotherapy, pulmonary embolism, superior vena cava syndrome, ${ }^{79}$ or decreased oncotic pressure. Chest radiography showing massive pleural effusion increases the probability of a malignant etiology. Radiographic signs of a malignant pleural effusion include circumferential lobulated pleural thickening, crowding of the ribs, and elevation of the hemidiaphragm or ipsilateral mediastinal shift consistent with lung atelectasis due to airway obstruction by a tumor.

Contrast-enhanced CT shows Leung's criteria, ${ }^{80,81}$ ie, circumferential, nodular pleural, and parietal pleural thickening greater than $1 \mathrm{~cm}$, and mediastinal pleural involvement or evidence of a primary tumor (Table 5). Each of these findings has a reported specificity of $22 \%-56 \%$ and a sensitivity of $88 \%-100 \%{ }^{82}$ The sensitivity of closed needle biopsy for adenocarcinoma is reported to be $69 \%$ when adequate tissue is obtained. ${ }^{79}$ In a randomized study, Maskell et al observed higher diagnostic yields with CT-guided biopsy compared with closed pleural biopsy, with sensitivities of $87 \%$ and $47 \%$ and specificities of $100 \%$ for both. The negative predicted values for both were $80 \%$ and $44 \%$, respectively. ${ }^{83}$ Thoracoscopy has a $90 \%-100 \%$ sensitivity for malignant pleural effusion. ${ }^{84}$

Management of malignant pleural effusions begins with therapeutic thoracocentesis. If symptoms do not improve with large-volume thoracocentesis, alternative causes of dyspnea should be considered. These could be microtumor emboli, lymphangitic cancer, the effects of chemotherapy or radiotherapy, or pulmonary thromboembolism. The removal of a large volume of pleural fluid could rapidly expand atelectatic lung regions beyond their capacity to reinflate and cause alveolar capillary injury, resulting in re-expansion pulmonary edema. ${ }^{85}$ Although symptoms can improve after thoracocentesis, $98 \%-100 \%$ of patients with malignant pleural effusion experience reaccumulation of fluid and recurrence of symptoms within 30 days. ${ }^{86,87}$

Immunocytochemistry, as an adjunct to cell morphology, is becoming increasingly helpful in distinguishing benign

Table 5 Leung's criteria ${ }^{80,81}$ for computed tomographic scan findings of malignant effusion

Circumferential pleural thickening

Nodular pleural thickening

Parietal pleural thickening $>1 \mathrm{~cm}$

Mediastinal pleural involvement 
from malignant mesothelial cells and mesothelioma from adenocarcinoma. ${ }^{88}$ When malignant cells are identified, the glandular markers for carcinoembryonic antigen, B72.3, and Leu-M1, together with calretinin and cytokeratin 5/6, will often help to distinguish adenocarcinoma from mesothelioma. ${ }^{89,90}$

\section{Pleural effusion associated with rheumatoid arthritis}

Inflammatory pleural effusions are an uncommon complication seen in about $2 \%-5 \%$ of patients with rheumatoid arthritis. ${ }^{91}$ Pleural involvement is the most common thoracic manifestation of rheumatoid disease. ${ }^{92}$ Effusions typically occur during evolution of established rheumatoid arthritis, but occasionally they are seen with the onset of arthritic symptoms or in the absence of arthritic disease. ${ }^{93}$ These effusions are typically unilateral, but bilateral effusions may also be seen. Fluid is generally serous or turbid, and exudative with lymphocytic predominance. Polymorphonuclear predominance is seen in the early stages. The pleural fluid glucose level is usually $<30 \mathrm{mg} / \mathrm{dL}$. ${ }^{94}$ It has been postulated that selective blockade of glucose transfer from the blood to the pleural space is responsible for this finding. ${ }^{95}$ The low $\mathrm{pH}$ of 7.0-7.13 is due to impairment of the transfer of acidic anerobic metabolites across an inflamed pleura. ${ }^{96}$ The adenosine deaminase level in pleural fluid is $>50 \mathrm{U} / \mathrm{L}$. Distinction between rheumatoid effusions and empyema becomes difficult, but findings of elevated pleural fluid rheumatoid factor (titer 1:320) and low $\mathrm{C}_{4}$ complement levels $(0.03 \mathrm{~g} / \mathrm{dL})$ help in distinguishing the two conditions. These effusions are selflimiting over several weeks. Sometimes pleural thickening with fibrothorax develops and requires decortication.

\section{Pleural effusion associated with systemic lupus erythematosus}

Pleural involvement occurs during the course of systemic lupus erythematosus in $50 \%-75 \%$ of patients and can be the presenting manifestation. ${ }^{97}$ One mechanism suggested for the production of pleural effusion is deposition of remotely generated immune complexes in the pleural capillaries. These complement fragments increase vascular permeability, allowing fluid and proteins to escape into the pleural space. Fluid is exudative, with a polymorphonuclear predominance and $\mathrm{pH}>7.36$, glucose $>60 \mathrm{mg} \%$, and lactate dehydrogenase $\leq 600 \mathrm{U} / \mathrm{L}$. Diagnosis of lupus is likely if the fluid is positive for lupus erythematosus cells, antinuclear antibody is $>1: 160$, and the pleural fluid/serum antinuclear antibody ratio is more than $1 . .^{98}$

\section{Pleural effusion associated with amebic abscess of liver}

The pathogenesis of amebic pleural effusion is related to diaphragmatic irritation resulting in sympathetic effusion or rupture of an amebic hepatic abscess through the diaphragm into the pleural space. ${ }^{99,100}$ Rupture of an abscess into the right pleural space is manifested by acute right upper quadrant pain, respiratory distress, and sepsis. ${ }^{101,102}$ Diaphragmatic irritation from a hepatic abscess may result in a pleural friction rub, pleural reaction on chest radiography, and a serous pleural effusion. Chest radiography shows an elevated right hemidiaphragm, plate-like atelectasis, and small right pleural effusion. Usually it is right-sided effusion and the fluid is the color of anchovy sauce, exudative, and with polymorphonuclear predominance. Ultrasonography is diagnostic, showing abscess in the liver with disruption of the diaphragm. Entamoeba histolytica can be isolated from the fluid.

\section{Hydatidothorax}

Hydatid cyst disease is caused by the larval stage of Echinococcus granulosus. Extrapleural hydatid cysts are rare and can be located in the fissures, pleural cavity, chest wall, mediastinum, myocardium, and diaphragm. ${ }^{103}$ Although daughter cysts in pleura and pleural complications of primary pleural hydatid disease have been reported, primary extrapulmonary hydatids are extremely rare. ${ }^{104}$ Thameur et al reported an incidence of 5.62\% of extrapulmonary hydatidosis in their review of 1619 cases of thoracic hydatidosis. ${ }^{105}$ Patients with a cyst in the pleural cavity present with chronic cough, dyspnea, and chest pain. CT scanning is the main diagnostic tool for thoracic hydatidosis.

\section{Pleural effusion associated with pancreatitis}

Pancreatitis-related pleural effusions are largely due to the close proximity of the pancreas to the diaphragm. Effusions can occur with either acute or chronic pancreatitis with different clinical presentation, management, and prognosis. Mechanisms involved in the pathogenesis include direct contact of pancreatic enzymes with the diaphragm, giving rise to sympathetic effusion, transfer of ascitic fluid via transdiaphragmatic lymphatics or diaphragmatic defects, communication of a fistulous tract between a pseudocyst and pleural space, and retroperitoneal movement of fluid into the mediastinum with mediastinitis or rupture into the pleural space. ${ }^{106,107}$ The pleural effusion associated with acute pancreatitis is usually small and left-sided in $60 \%$ of cases; however, $30 \%$ are right-sided and $10 \%$ are bilateral. 
Fluid is a hemorrhagic exudate with polymorphonuclear predominance. The $\mathrm{pH}$ is 7.32-7.5 and the glucose concentration is similar to the serum glucose level. In acute pancreatitis, effusions are small, with an increase in both serum and pleural fluid amylase. These effusions resolve rapidly once the pancreatitis resolves. There is massive effusion in chronic pancreatitis due to rupture of pseudocyst with pancreaticopleural fistula. There is also an increase in pleural fluid amylase in chronic pancreatitis, but serum amylase is normal. Patients typically present with a history of repeated episodes of alcoholic pancreatitis. Pancreatic calcifications on ultrasonographic or CT scans are diagnostic.

\section{Pleural effusion associated with hepatitis}

These are usually small effusions and are immunological in origin. Fluid is dark, with yellow exudates and a small number of lymphocytes. Pleural fluid amylase is low and glucose is similar to blood glucose. Hepatitis B surface antigen and e antigen can be detected in the fluid. Effusion generally resolves prior to resolution of hepatitis. ${ }^{108}$

\section{Pleural effusion associated with esophageal perforation}

The pleural fluid findings in spontaneous esophageal rupture will depend on the degree of perforation and the timing of thoracocentesis in relation to the injury. Early thoracocentesis without mediastinal perforation will show sterile serous exudates with polymorphonuclear predominance. Pleural fluid amylase and $\mathrm{pH}$ will be normal. Once the mediastinal pleura tears, amylase of salivary origin will appear with higher concentration. As the pleural space is seeded with anerobes from the mouth, the $\mathrm{pH}$ may reduce to approximately 6.0. Squamous epithelial cells and food particles will be present. ${ }^{109}$

\section{Chylothorax}

A pleural effusion that contains chyle is known as a chylothorax. DeMeester classified chylothorax into congenital, traumatic, neoplastic, and miscellaneous. ${ }^{110}$ In the traumatic type, patients present with cough, dyspnea, and chest discomfort. Pleuritic chest pain and fever are uncommon because chyle is not irritating to the pleural surface. The severity of symptoms depends on the size of the chylothorax. The course of the thoracic duct explains why injury to the duct above the level of the fifth thoracic vertebra usually produces left-sided chylothorax and injury below that level produces a right-sided chylothorax. ${ }^{111}$ The pleural fluid is characteristically milky in appearance (Figure 12). A chylothorax is an odorless exudate with a predominance of lymphocytes. Electron microscopy

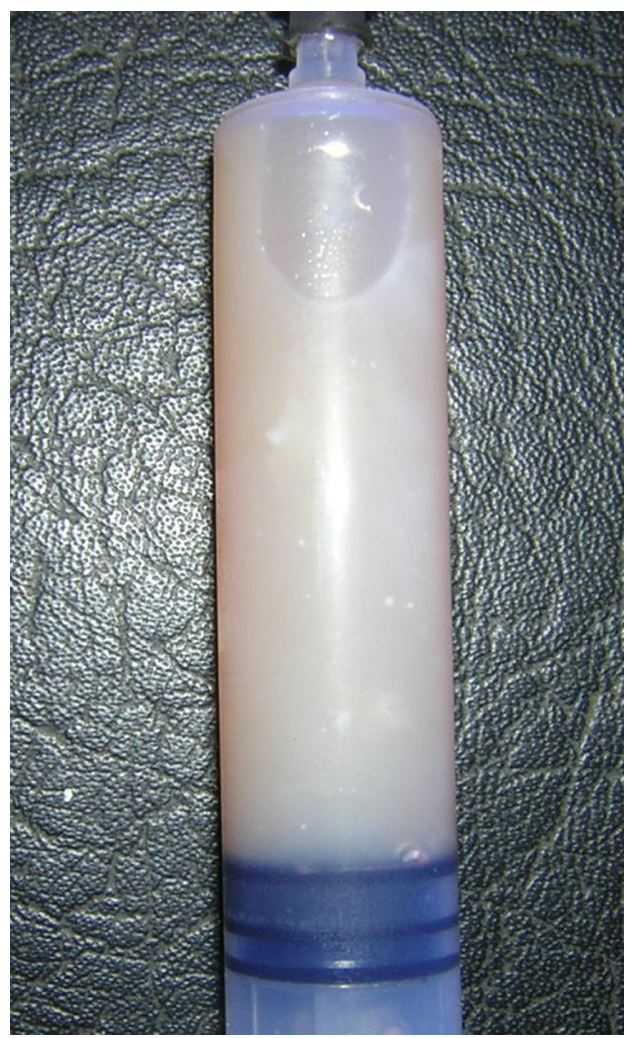

Figure 12 Chylous fluid.

shows chylomicrons. Chylomicrons stain with Sudan III stain. Triglyceride levels $>110 \mathrm{mg} / \mathrm{dL}$, presence of chylomicrons, low cholesterol levels, elevated lymphocyte count, pleural fluid to serum triglyceride ratio $>1$, and a pleural fluid to serum cholesterol ratio $<1$ are diagnostic.

Chylothorax needs to be differentiated from pseudochylothorax. Pseudochylothorax is more likely to result from long-standing pleural effusion. High cholesterol levels are typical of a pseudochylous pleural effusion. Cholesterol levels are generally $>200 \mathrm{mg} / \mathrm{dL}$ and may even exceed $1000 \mathrm{mg} / \mathrm{dL} .{ }^{12}$ The fluid may demonstrate rhomboidshaped cholesterol crystals on electron microscopy, which do not stain with Sudan III stain. Tuberculosis accounts for approximately $54 \%$ of all cases. Rheumatoid arthritis and trapped lung are rare causes. ${ }^{113}$ The ether test can be used to distinguish chylous from pseudochylous effusions. In the event of pseudochylothorax, there will be clearing of fluid as a result of dissolution of cholesterol with ether.

\section{Pleural effusion associated with Meigs syndrome}

In 1937, Meigs and Cass ${ }^{114}$ reported seven patients with ovarian fibroma associated with ascites and hydrothorax. This syndrome can occur with other tumors of the ovary. ${ }^{115}$ 
When the ovarian tumor is removed, the ascites and pleural effusion resolve. The fluid moves into the pleural space through small diaphragmatic lymphatics, because of the pressure gradient across the diaphragm. The fluid is a yellowcolored exudate with a paucity of mononuclear cells.

\section{Pleural effusion associated with radiation therapy}

Radiation therapy can cause pleural effusion by two mechanisms, ie, radiation pleuritis and systemic venous hypertension or lymphatic obstruction from mediastinal fibrosis. Bachman and Macken ${ }^{116}$ have reported patients with carcinoma of the breast who developed ipsilateral pleural effusions due to radiation pleuritis. Patients are either asymptomatic or complain of pleuritic chest pain. The effusion is usually hemorrhagic with multiple reactive mesothelial cells. Pleural effusions can result from radiation therapy not associated with radiation pleuritis. These effusions tend to occur 1-2 years following completion of intensive mediastinal radiation. Mechanisms for development of pleural effusion as a late complication of radiation therapy include constrictive pericarditis, superior vena cava obstruction, and lymphatic obstruction.

\section{Pleural effusion associated with trapped lung}

A trapped lung occurs when a fibrous membrane covers a portion of the visceral pleura, preventing that part of the lung from expanding to the chest wall. This situation results in a constant-volume, recurrent pleural effusion known as "effusion ex vacuo". ${ }^{117}$ Due to the inability of the lung to expand to the chest wall, intrapleural pressure becomes more negative and favors fluid accumulation in the pleural space until a new steady state is reached. The diagnosis should be suspected in an asymptomatic individual with a chronic unilateral effusion that recurs rapidly following thoracocentesis. The effusion is a serous transexudate with a small number of mononuclear cells. CT scan shows the split pleura sign, confirming the diagnosis.

\section{Transudative effusion \\ Pleural effusion associated with congestive heart failure}

Patients with congestive heart failure and pleural effusion present with orthopnea, paroxysmal nocturnal dyspnea, and on examination have fine crackles. Chest X-ray shows cardiomegaly and bilateral pleural effusions, generally the right effusion being larger than the left. These are transudative effusions but may present with transexudates in patients who are on diuretic therapy. The pleural to serum-effusion albumin gradient will be greater than $1.2 \mathrm{~g} / \mathrm{dL}$ even after diuresis. ${ }^{118}$ Serum and pleural fluid NT-proBNP levels are significantly elevated in patients with pleural effusion owing to heart failure. Hence they are of high diagnostic value in the diagnosis of heart failure-related pleural effusion. ${ }^{119}$ The effusions usually improve quickly once diuretic therapy is started. Therapeutic tapping is needed only if the patient has respiratory embarrassment. In patients with clinical or radiological evidence of congestive heart failure, investigation of the effusion need not go any further.

\section{Pleural effusion associated with cirrhosis of liver}

Hepatic hydrothorax is a pleural effusion that develops in a patient with pulmonary hypertension in the absence of cardiopulmonary disease. Effusion is caused by passage of ascitic fluid from the peritoneal cavity into the pleural space through diaphragmatic defects. ${ }^{120,121}$ Up to $20 \%$ of patients with hepatic hydrothorax have no clinically demonstrable ascites. ${ }^{122}$ Clinical signs of liver cirrhosis may be present. Effusions may be unilateral (17\%) or bilateral (3\%). Massive effusions occur in about $6 \%$ of patients. It is usually a serous or hemorrhagic transudate, with predominantly lymphocytes and mesothelial cells. Pleural fluid and ascitic fluid show similar biochemistry. Increasing effusion is often associated with a decrease in ascitic fluid. ${ }^{123}$

\section{Pleural effusion associated with peritoneal dialysis}

Peritoneal dialysis is frequently associated with small bilateral pleural effusions, but occasionally massive right pleural effusions are seen. ${ }^{124}$ It occurs within 30 hours after initiation of peritoneal dialysis, sometimes even after months or years of beginning dialysis. Fluid is serous and generally resembles dialysate. Total protein is usually $<1 \mathrm{~g} / \mathrm{dL}$ with a leucocyte count of $<100 / \mu \mathrm{L}$, predominantly mononuclear. Rapid movement of radiolabeled tracer from the peritoneal to pleural cavity confirms the diaphragmatic defect if there is doubt about diagnosis. ${ }^{125}$ Pleural fluid resolves after fluid is removed from peritoneum. Alternative hemodialysis should be used.

\section{Urinothorax}

Pleural effusion secondary to obstructive uropathy is known as urinothorax. Pleural fluid can be right-sided or leftsided, depending on the side of obstructive hydronephrosis. Urinothorax occurs due to perinephric urine leak, which 
passes through diaphragmatic defects to pleura. It smells like urine. Stark et al ${ }^{126}$ have demonstrated that patients with urinothorax have a pleural fluid creatinine to serum creatinine ratio of $>1.0$. Effusion resolves with treatment of the primary problem.

\section{Pleural effusion associated with nephrotic syndrome}

Approximately $20 \%$ of patients with nephrotic syndrome develop pleural effusion. ${ }^{127}$ Effusions result from severe hypoalbuminemia, which leads to decreased oncotic pressure. They are bilateral effusions, serous in nature with proteins $<1 \mathrm{~g} / \mathrm{dL}$, with normal glucose and $\mathrm{pH}>7.4$.

\section{Benign pleural effusion}

These are self-limiting effusions where diagnostic thoracocentesis is not required.

\section{Viral infection}

Patients present with acute symptoms of febrile illness, dry cough, and chest pain. Radiological findings may show associated pneumonia. These are small effusions, ie, serous exudates with few mononuclear cells. However, acute viral pleurisy may present with polymorphonuclear predominance. Effusions are self-limiting, and usually resolve within 2 weeks.

\section{Postcardiac injury syndrome}

Postcardiac injury syndrome was first described in the 1950 s in patients undergoing mitral commissurotomy and other cardiac surgeries. ${ }^{128}$ Postcardiac injury syndrome has been described as occurring after myocardial infarction, ${ }^{129}$ pulmonary embolism, ${ }^{130}$ pacemaker implantation, ${ }^{131}$ chest trauma, ${ }^{132}$ and a variety of cardiac insults. The cause of postcardiac injury syndrome is still unclear, although there is some evidence to support an immunological or viral origin. ${ }^{133}$ Patients may present with other signs and symptoms, such as hemoptysis, arthralgias, arthritis, and unexplained anemia. The degree of myocardial damage does not correlate directly with the development of postcardiac injury syndrome, which also implies an immunological basis for the syndrome. Small effusions resolve spontaneously. Salicylates, other nonsteroidal anti-inflammatory drugs, or corticosteroids should be used for the symptomatic patient or those with large-to-moderate symptomatic pleural effusion. ${ }^{134}$

\section{Atelectasis}

These effusions are seen in postoperative patients especially following upper abdominal surgery and in patients in medical intensive care units. Patients may present with fever and breathlessness. Effusion is transudative, but over a time it may change to exudate. They are self-limiting effusions for a short period when the underlying cause is treated.

\section{Asbestos-related pleural effusion}

Effusions occur due to asbestos exposure. Prevalence is dose-related and varies from $0.2 \%$ to $7 \%$ with severe asbestos exposure. Pleural effusion can be early, occurring in the first year or can be late, occurring after 20 years. The majority of patients are asymptomatic, and are discovered usually on routine chest radiography. Pleural effusion is usually unilateral and small, but may be large or bilateral in $10 \%$ of cases. Pleural plaques can be seen, with pleural thickening in $20 \%$ of cases. The designation "benign" refers to the lack of evidence of malignancy, and diagnosis depends on a history of asbestos exposure and exclusion of other specific causes. ${ }^{135}$ The effusion is an exudate, often bloodstained, with no characteristics on pleural fluid analysis. Pleural biopsy is frequently required to rule out other causes of pleural effusions, including mesothelioma. The usual pathological findings are a chronic fibrous pleurisy with minimal cellularity. Effusions resolve without treatment within a month to a year, with a mean duration of 3-4 months, and recurrence is common. A long-term follow up of 3 years is required to exclude malignancy for a fully established diagnosis of benign nature.

\section{Associated with diabetes mellitus}

The effusions are transudative and could be related to left ventricular dysfunction and congestive heart failure. Effusions are incidental findings and resolve spontaneously. ${ }^{136}$

\section{Hypothyroidism-related pleural effusion}

Patients with hypothyroidism develop pleural effusions from other causes or related to their state of reduced thyroid function, such as pericardial fluid, congestive heart failure, or ascites. ${ }^{137}$ A pleural capillary leak may be a mechanism responsible. ${ }^{138}$ Patients with hypothyroid pleural effusions are asymptomatic and require no therapeutic intervention except thyroid hormone replacement therapy.

\section{Postpartum pleural effusion}

Normal pregnancy could promote transudation of fluid into the pleural space because of increased hydrostatic pressure in the systemic circulation, increased blood volume, and decreased colloid osmotic pressure. ${ }^{139}$ Repeated Valsalva maneuvers further promote pleural effusion because of increased intrathoracic pressure and impaired lymphatic 
drainage of the pleural space through elevation of systemic venous pressure. Atelectasis from a gravid uterus could also lead to accumulation of pleural fluid. ${ }^{140,141}$

\section{Management}

Treatment of the specific cause, drainage of fluid, pleurodesis, and surgical management are the therapeutic options for pleural effusion.

\section{Treatment of specific cause}

The specific treatment of pleural effusion depends on the etiology. Treatment of the underlying cause helps resolve most transudative effusions. Effusions associated with connective tissue disorders like rheumatoid arthritis and systemic lupus erythematosus are treated with steroids, and resolution may occur within 2 weeks. Tuberculous pleural effusions are treated with short-course antituberculosis therapy, ie, 2 months of isoniazid, rifampicin, pyrazinamide, and ethambutol, followed by 4 months of isoniazid and rifampicin. Controlled trials have shown no benefit of using steroids along with antituberculosis therapy. ${ }^{142}$

Amebic pleural effusions are treated with metronidazole $800 \mathrm{mg}$ three times daily for 5-10 days followed by diloxanide furoate $500 \mathrm{mg}$ three times daily for 10 days. Pleural hydatidosis needs surgical management with excision of cysts and decortication, along with albendazole $400 \mathrm{mg}$ once daily for one month prior to surgery. At the time of opening of the parietal pleura, care should be taken to avoid accidental incision over a cyst, because the intrapleural cysts lie immediately below the parietal pleura. A careful dissection of the wall of the cyst is needed without injuring the visceral pleura, which may lead to persistent postoperative air leak and bronchopleural fistula. Pancreatitis-related pleural effusions need conservative management with somatostatins and octreotide for spontaneous closure of fistula. ${ }^{143}$ Tube thoracostomy for recurrent effusions with respiratory embarrassment, and bowel and pancreatic rest is the treatment of choice. Congestive cardiac failure-related effusions usually improve quite quickly when diuretic therapy is started. Diagnostic thoracocentesis is required only if a patient has bilateral effusions that are unequal in size, has effusion that does not respond to therapy, presents with pleuritic chest pain, or is febrile. ${ }^{144,145}$ Hepatic hydrothorax needs sodium restriction and diuresis. Repeated thoracocentesis will result in volume and protein depletion. Hence, no more than $1.5 \mathrm{~L}$ of fluid should be removed at one time to avoid reperfusion pulmonary edema. Patients with trapped lung who are asymptomatic need reassurance and observation, while symptomatic patients should be considered for decortication after evaluation of disability status. In Meigs syndrome, removal of the ovarian mass results in resolution of ascites and pleural effusion within 2-3 weeks. Patients with chylothorax require aggressive nutritional support with a diet rich in low-fat, medium-chain triglycerides which are absorbed directly into the portal circulation to reverse hypovolemia, immunosuppression, and protein and electrolyte deficiencies. Therapeutic thoracocentesis is needed in large chylothoraces that cause respiratory distress. Malignant chylothorax is treated with radiotherapy and/or chemotherapy. Surgical therapy, ie, thoracic duct ligation is recommended for post-traumatic or postsurgical chylothorax. Malignant effusions are treated with chemotherapy, radiotherapy, and rarely surgery. Repeat thoracocentesis should be reserved for patients who reaccumulate pleural effusions slowly after each thoracocentesis, patients who have cancers that commonly respond to therapy with resolution of the associated effusions, those who appear unlikely to survive beyond 1-3 months, and those who cannot tolerate other more interventional procedures to control pleural fluid, such as pleurodesis. ${ }^{146}$

Pleurodesis is the treatment of choice for recurrently filling effusions. Successful pleurodesis requires opposition of the visceral and parietal pleurae. Patients with airway obstruction from an endobronchial tumor, extensive intrapleural tumor masses, or multiple pleural loculations resulting in trapped lungs are unlikely to respond. A review of the English literature for 1168 patients treated with chemical agents for malignant pleural effusions from 1966 to 1994 showed that talc was the most effective sclerosing agent, with a complete success rate of 93\% compared with other agents. ${ }^{147}$ Sclerosants are instilled only when catheter drainage has decreased to less than $150 \mathrm{~mL}$ /day and the chest catheter may be removed after sclerosant instillation when drainage returns to less than $150 \mathrm{~mL} /$ day. Thoracoscopy produces effective pleurodesis in $71 \%-97 \%$ of patients. ${ }^{148,149}$

The management of empyema (Figure 13) consists of prompt initiation of appropriate antibiotics, drainage of pus, and restoration of lung expansion. Needle thoracocentesis for chemistry analysis, Gram staining, and culture are mandatory for confirmation of diagnosis. Thoracocentesis and antibiotics alone have been successful in treatment of empyema in $6 \%-20 \%$ of patients, particularly those with early-stage disease. Closed tube thoracostomy using underwater drainage has success rates of $24 \%-78 \%$. Response to therapy is assessed by defervescence of fever. Anerobic infections may take 7-8 days for the fever to subside. Patients who fail to respond to intercostal tube drainage and antibiotic 


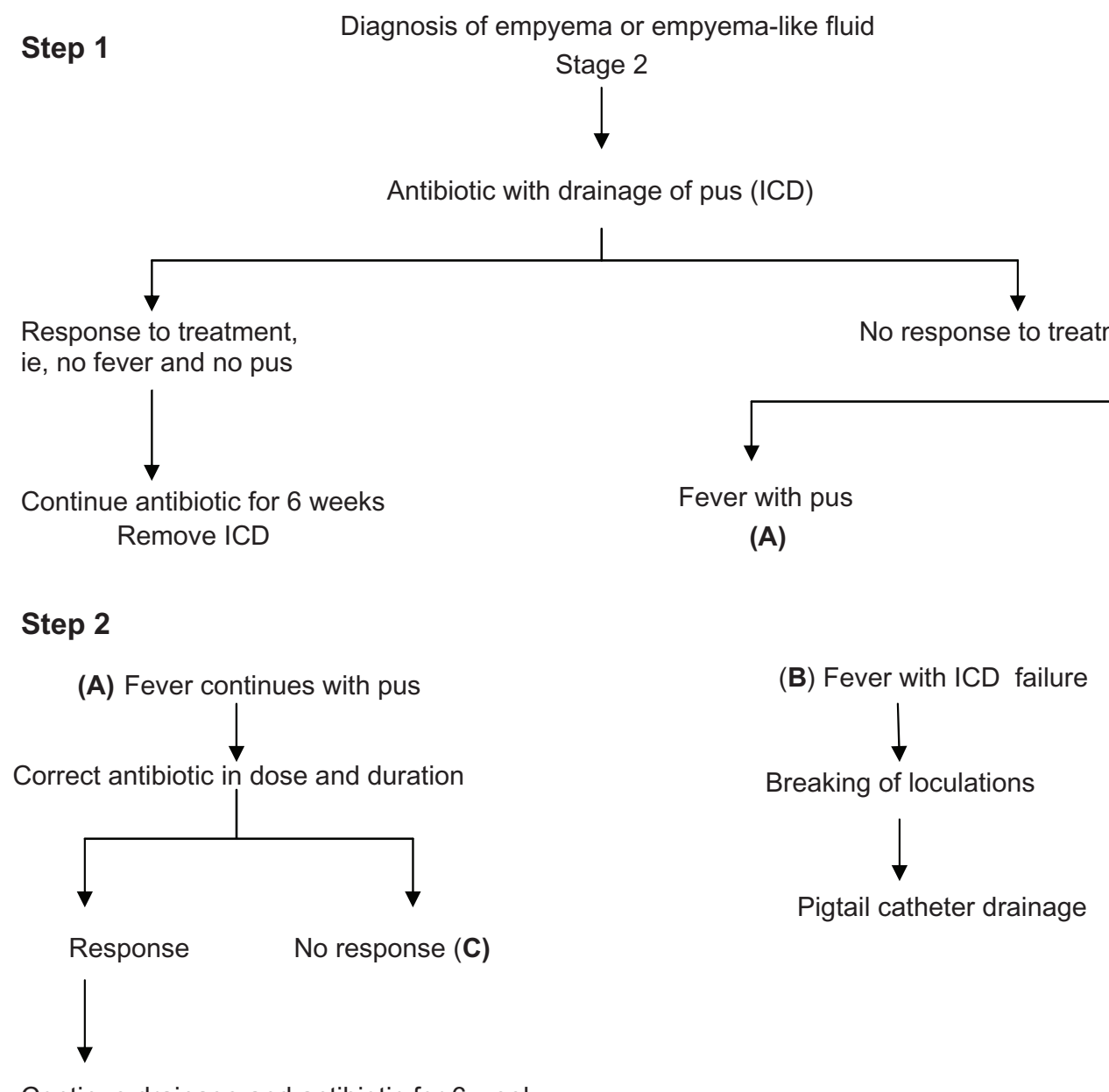

Continue drainage and antibiotic for 6 week

\section{Step 3}

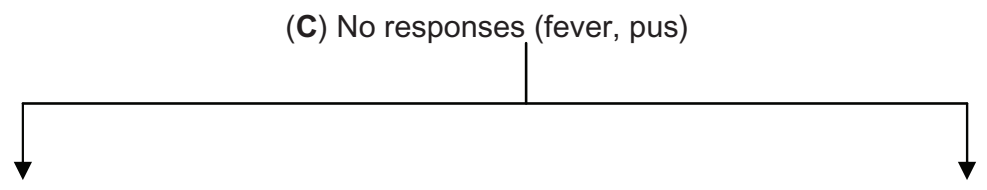

Patient fit for surgery

Early decortications

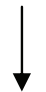

For removal of nidus of infection
Patient unfit for surgery

Window operation

Fenestration operation Thoracoplasty

Figure 13 Management of empyema.

Abbreviation: ICD, intercostal drain.

therapy need direct removal of the restrictive peel with open or thoracoscopic technique in the early or later stages. The American College of Chest Physicians has developed a classification to assist practicing physicians in managing patients with empyema. ${ }^{150}$ The management of bronchopleural fistula merits a long-term trial of an intercostal tube from a few weeks to months along with chemotherapy.

\section{Drainage}

Therapeutic tapping is needed only if the patient has respiratory embarrassment. Breathlessness in pleural effusion is primarily due to paradoxical movement of an inverted hemidiaphragm. ${ }^{151}$ Clinically, inversion of the diaphragm results in paradoxical movement of the affected side. The vital capacity and alveolar ventilation is reduced, with resultant 
hypoxemia and dyspnea. Estenne et al ${ }^{152}$ suggested that relief of dyspnea after thoracocentesis results primarily from reduction in size of the thoracic cage, which allows the inspiratory muscles to operate on a more advantageous portion of their length-tension curve. Another study showed improvement of gas exchange as a result of an improved ventilation-perfusion ratio due to increase in the ventilation of parts of the lung previously poorly ventilated but perfused. ${ }^{153}$

Drainage can be done by intercostal tubes or pigtail catheters. These are traditionally attached to an underwater drain consisting of reusable glass units (Figure 14). Ambulatory chest drainage devices that use a mechanical 1-way valve with collection bags (flutter bags) are an alternative to the traditional underwater drain. The urinary collection bag (Urosac, Figure 15) functions on the same principle as the specially designed chest drainage bags, and therefore can be used as a cheap and easily available substitute. They are less bulky and allow the patient to be ambulatory, thus reducing the risk of complications from immobility and can be used on an inpatient and outpatient basis. ${ }^{154}$ The Urosac used as a chest drainage bag has been shown to be a safe, effective, and economical alternative in several studies. ${ }^{155}$ In patients with accidental slippage of intercostal tubes and pleurocutaneous

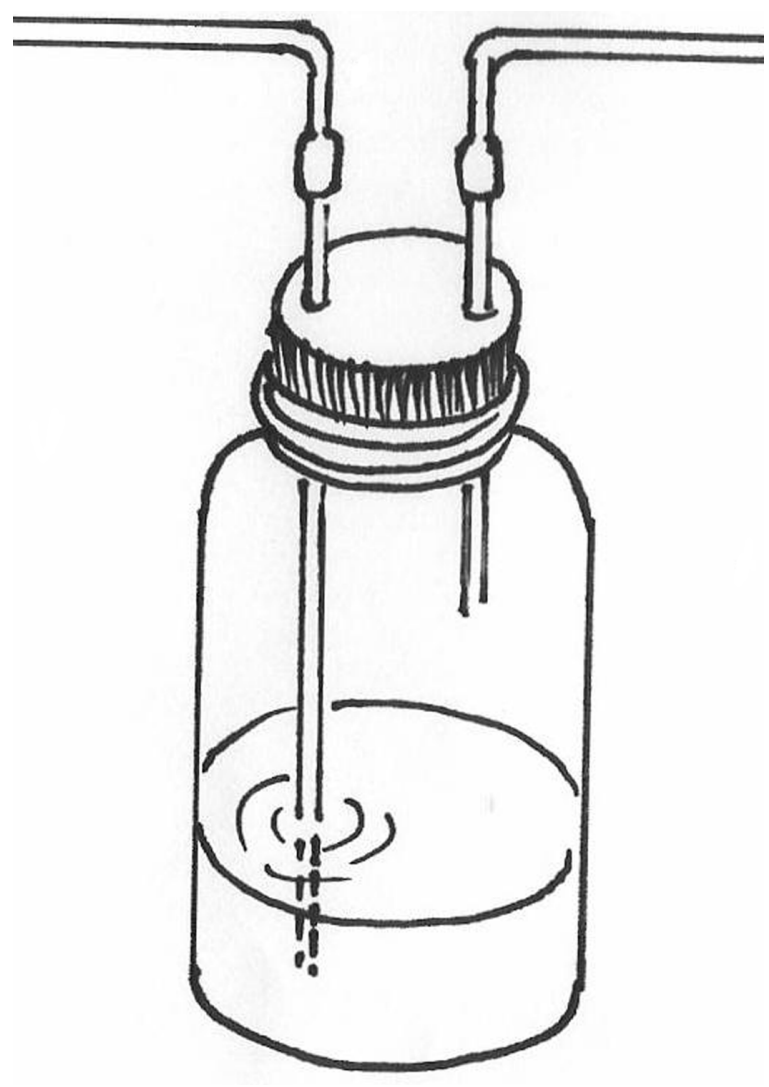

Figure I 4 Intercostal drainage with underwater drain using glass bottle.

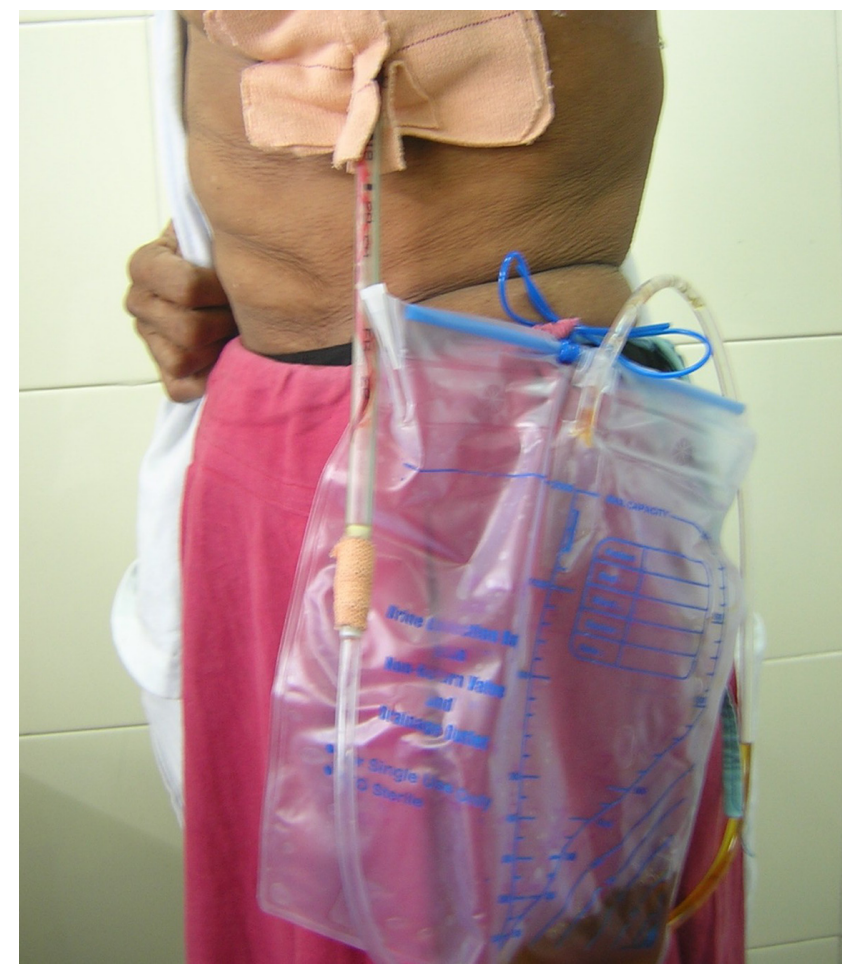

Figure 15 Intercostal drainage with Urosac bag.

fistulae, drainage can be performed without intercostal tubes and attachment of chest seals (stoma bags) which remain adherent to the chest wall (Figure 16). Stoma bags may not be advisable for recurrent massive effusions.

\section{Pleurodesis}

Pleurodesis refers to the insertion of a chest tube and instillation of sclerosing chemical substances into the pleural cavity and production of adhesions between the outer surface of the lung and inner surface of the chest wall, in order to prevent accumulation of fluid or air in the pleural space. This procedure is the most effective and least invasive of all the surgical procedures available to control pleural effusion, especially those of malignant etiology. It is important to demonstrate the ability to oppose the visceral and parietal pleura prior to attempting pleurodesis. Pleurodesis should not be attempted in patients whose expected survival is short. According to Sudduth and Sahn, ${ }^{156}$ the following three criteria must be met: the effusion must be symptomatic; the presence of a trapped lung should be excluded; and pleurodesis should be reserved for those cases where there is no other therapeutic alternative or when this has already failed. Although the main indication for pleurodesis in effusions is pleural malignancy, pleurodesis may be required in certain benign conditions responsible for recurrent effusions, such as cardiac failure, cirrhosis of the 


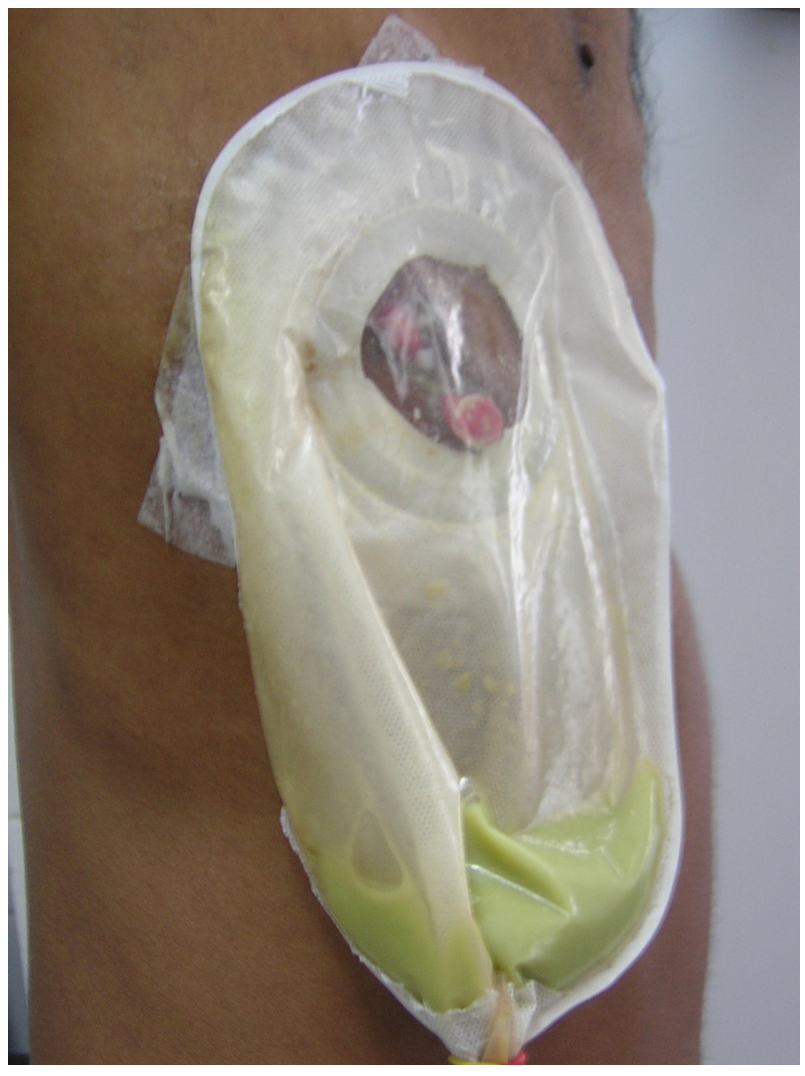

Figure 16 Stoma bag for pleurocutaneous fistula.

liver, nephrotic syndrome, chylothorax, or systemic lupus erythematosus. Vargas et $\mathrm{al}^{157}$ have reported their experience using low-dose $(2 \mathrm{~g})$ talc in such conditions, with a very good rate of success. More than 30 agents have been proposed as sclerosants to induce pleurodesis. Commonly used sclerosants are tetracycline hydrochloride, doxycycline, bleomycin, quinacrine, talc, and povidone iodine.

\section{Surgical management}

Decortication, pleurectomy, pleuropneumonectomy, closure of bronchopleural fistula with or without grafting, window operation, fenestration surgery, thoracostomy, and thoracoplasty are the various surgical modalities available. However, there is no gold standard method mentioned in the literature to treat empyema. A review by Molnar mentions that no exclusive procedure with a uniformly predictable successful outcome is available for the treatment of empyema, and suggests an individualized approach based on institutional practice and local protocols. ${ }^{158}$ Surgery may be needed for malignant pleural involvement, empyema with or without bronchopleural fistula, and fibrothorax. In empyema, which is the most common indication for surgery, it should be borne in mind that control of infection, and not impairment of lung function, is the only imperative reason for surgery in the first few weeks of treatment. Early decortication should be planned for patients not responding to appropriate antibiotics and drainage, along with persistence of fever, provided they are fit for decortication. Window fenestration or thoracoplasty can be planned for those who are not fit for decortication. Late decortication to restore impaired lung function is usually planned after several months of completion of chemotherapy because studies have shown that, with adequate conservative management, pleural peel resolves in most cases, with restoration of lung function in several months, and decortication need not be performed routinely. ${ }^{159}$ Disability assessment for the need to perform late decortication should be done only in patients with a nonsedentary lifestyle in whom impaired lung function hampers routine activities. In empyema complicated with bronchopleural fistula which does not respond to conservative management, including long-term drainage, thereby causing recurrent pleural infections, surgical intervention, eg, decortication, pleuropneumonectomy, or pleurolobectomy, along with closure and grafting of the fistula or a thoracoplasty may be needed. ${ }^{160}$ In fibrothorax, which is usually a consequence of long-standing empyema, the duration of disease is not of much importance with regard to consideration of decortication, provided the underlying lung parenchyma is normal. This has been shown by a previous study which documented an objective functional improvement following decortication after 20 years of fibrothorax. ${ }^{161}$

\section{Disclosure}

The authors report no conflicts of interest in this work.

\section{References}

1. Collins TR, Sahn SA. Thoracocentesis: clinical value, complications, technical problems and patient experience. Chest. 1987;91: 817-822.

2. Sahn SA, Heffner JE. Approach to the patient with pleurisy. In: Kelly WN, editor. Kelly's Textbook of Internal Medicine. 2nd ed. Philadelphia: Lippincott, Williams and Wilkins; 1991.

3. Porcel JM, Light RW. Diagnostic approach to pleural effusion in adults. Am Fam Physician. 2006;73:1211-1220.

4. Stelzner TJ, King TE, Antony VB, Sahn SA. Pleuropulmonary manifestations of the postcardiac injury syndrome. Chest. 1983;84: 383-387.

5. Uong V, Nugent K, Alalawi R, Raj R. Amiodarone-induced loculated pleural effusion: case report and review of the literature. Pharmacotherapy. 2010;30:218.

6. Singh SK, Ahmad Z, Pandey DK, Gupta V, Naaz S. Isoniazid causing pleural effusion. Indian J Pharmacol. 2008;40:87-88.

7. Huggins JT, Sahn SA. Drug-induced pleural disease. Clin Chest Med. 2004;25:141-153.

8. Blesovsky A. The folded lung. Br J Dis Chest. 1966;60:19-22.

9. Stark P. Round atelectasis: another pulmonary pseudotumor. Am Rev Respir Dis. 1982;125:248-250. 
10. Doyle TC, Lawler GA. CT features of rounded atelectasis of the lung. AJR Am J Roentgenol. 1984;143:225-228.

11. Byrk D. Infrapulmonary effusions. Radiology. 1976;120:33-36.

12. Schwarz MI, Marmorstein BL. A new sign of subpulmonic effusion. Chest. 1975;67:176-178.

13. Gallardo X, Castaner E, Mata JM. Benign pleural diseases. Eur J Radiol. 2000;34:87-97.

14. Moskowitz H, Platt RT, Schachar R, Mellins H. Roentgen visualization of minute pleural effusion. An experimental study to determine the minimum amount of pleural fluid visible on a radiograph. Radiology. 1973;109:33-35.

15. Maher GG, Berger HW. Massive pleural effusions: malignant and non-malignant causes in 46 patients. Am Rev Respir Dis. 1972;105: 458-460.

16. Porcel JM, Vives M. Etiology and pleural fluid characteristics of large and massive effusions. Chest. 2003;124:978-983.

17. Pugatch RD, Spirn PW. Radiology of the pleura. Clin Chest Med. 1985;6:17-32.

18. Yu CJ, Yang PC, Wu HD, Chang DB, Kuo SH, Luh KT. Ultrasound study in unilateral hemithorax opacification. Image comparison with computed tomography. Am Rev Respir Dis. 1993;147:430-434.

19. Yang PC, Luh KT, Chang DB, Wu HD, Yu CJ, Kuo SH. Value of sonography in determining the nature of pleural effusion: analysis of 320 cases. AJR Am J Roentgenol. 1992;159:29-33.

20. Hamm H, Light RW. Parapneumonic effusion and empyema. Eur Respir J. 1997;10:1150-1156.

21. Tsai TH, Yang PC. Ultrasound in the diagnosis and management of pleural disease. Curr Opin Pulm Med. 2003;9:282-290.

22. Yataco JC, Dweik RA. Pleural effusions: Evaluation and management. Cleve Clin J Med. 2005;72:854-866.

23. Van Sonnenberg E, Nakamoto SK, Mueller PR, et al. CT and ultrasound guided catheter drainage of empyemas after chest tube failure. Radiology. 1984;151:349-353.

24. Stark DD, Federle MP, Goodman PC, Podrasky AE, Webb WR. Differentiating lung abscess and empyema. AJR Am J Roentgenol. 1983;141:163-167.

25. Stark DD, Federle MP, Goodman PC. CT and radiographic assessment of tube thoracostomy. Am J Roentgenol. 1983;141:253-258.

26. Algin O, Gökalp G, Topal U. Signs in chest imaging. Diagn Interv Radiol. 2011;17:18-29.

27. Leung AN, Muller NL, Miller RR. CT in differential diagnosis of diffuse pleural disease. AJR Am J Roentgenol. 1990;154:487-492.

28. Duysinx B, Nguyen D, Louis R, et al. Evaluation of pleural disease with 18-fluorodeoxyglucose positron emission tomography imaging. Chest. 2004;125:489-493.

29. Duysinx BC, Lorock MP, Nguyen D, et al. 18F-FDG PET imaging in assessing exudative pleural effusions. Nucl Med Commun. 2006;27: 971-976.

30. Bagga S. Rheumatoid lung disease as seen on PET/CT scan. Clin Nucl Med. 2007;37:753-754.

31. Orki, Akin O, Tasci AE, et al. The role of positive emission tomography/ computed tomography in the diagnosis of pleural diseases. Thorac Cardiovasc Surg. 2009;57:217-221.

32. Maskell NA, Butland RJ. BTS guidelines for the investigation of a unilateral pleural effusion in adults. Thorax. 2003;58 Suppl 2:ii8-ii17.

33. Porcel JM. Pearls and myths in pleural fluid analysis. Respirology. 2011;16:44-52.

34. Broaddus VC, Light RW. What is the origin of pleural transudates and exudates? Chest. 1992;102:658-659.

35. Light RW, MacGregor MI, Luchsinger PC, Ball WC Jr. Pleural effusions: the diagnostic separation of transudates and exudates. Ann Intern Med. 1972;77:507-513.

36. Heffner JE, Brown LK, Barbieri C. Diagnostic value of tests that discriminate between exudative and transudative pleural effusions. Chest. 1997;111:970-980.

37. Mitrouska I, Bouros D. The trans-exudative pleural effusions. Chest. 2002;122:1503-1505.
38. Romero S, Candela A, Martin C, Hernandez L, Trigo C, Gil J. Evaluation of different criteria for the separation of pleural transudates from exudates. Chest. 1993;104:399-404.

39. Burgess LJ, Maritz FJ, Taljaard JJ. Comparative analysis of the biochemical parameters used to distinguish between pleural transudates and exudates. Chest. 1995;107:1604-1609.

40. Heffner JE. Evaluating diagnostic tests in the pleural space. Differentiating transudates from exudates as a model. Clin Chest Med. 1998;19:277-293.

41. Light RW, Erozan YS, Ball WC Jr. Cells in pleural fluid. Their value in differential diagnosis. Arch Intern Med. 1973;132:854-860.

42. Adelman M, Albelda SM, Gottlieb J, Haponik EF. Diagnostic utility of pleural fluid eosinophilia. Am J Med. 1984;77:915-920.

43. Ferreiro L, San José E, González-Barcala FJ, et al. Eosinophilic pleural effusion: incidence, etiology and prognostic significance. Arch Bronconeumol. 2011;47:504-509.

44. Martinez-Garcia MA, Cases-Viedma E, Cordero-Rodriguez PJ, et al. Diagnostic utility of eosinophils in the pleural fluid. Eur Respir J. 2000;15:166-169.

45. Sahn SA. Pathogenesis and clinical features of diseases associated with a low pleural fluid glucose. In: Chretien J, Bignon J, Hirsch A, editors. The Pleura in Health and Disease. Volume 30. New York: Marcel Dekker; 1985.

46. Salyer WR, Eggleston JC, Erozan YS. Efficacy of pleural needle biopsy and pleural fluid cytopathology in the diagnosis of malignant neoplasm involving the pleura. Chest. 1975;67:536-539.

47. Adams RF, Gleeson FV. Percutaneous image-guided cutting-needle biopsy of the pleura in the presence of a suspected malignant effusion. Radiology. 2001;219:510-514.

48. Abrahms LD. A pleural biopsy punch. Lancet. 1958;1:30-31.

49. Morrone N, Algranti E, Barreto E. Pleural biopsy with Cope and Abrams needles. Chest. 1987;92:1050-1052.

50. Mungall IP, Cowen PN, Cooke NT, Roach TC, Cooke NJ. Multiple pleural biopsy with the Abrams needle. Thorax. 1980;35:600-602.

51. Cowie RL, Escreet BC, Goldstein B, Langton ME, Leigh RA. Pleural biopsy: a report of 750 biopsies performed using Abrams pleural biopsy punch. S Afr Med J. 1983;64:92-95.

52. Chakrabarti B, Ryland I, Sheard J, Warburton CJ, Earis JE. The role of the Abrams percutaneous pleural biopsy in the investigation of exudative pleural effusions. Chest. 2006;129:1549-1555.

53. James P, Gupta R, Christopher DJ, Balamugesh T. Evaluation of the diagnostic yield and safety of closed pleural biopsy in the diagnosis of pleural effusion. Indian J Tuberc. 2010;57:19-24.

54. Harris RJ, Kavuru MS, Rice TW, Kirby TJ. The diagnostic and therapeutic utility of thoracoscopy. A review. Chest. 1995;108:828-841.

55. Shaw P, Agarwal R. Pleurodesis for malignant pleural effusions. Cochrane Database Syst Rev. 2004;1:CD002916.

56. Tschopp JM, Boutin C, Astoul C, et al. Talcage by medical thoracoscopy for primary spontaneous pneumothorax is more cost-effective than drainage: a randomized study. Eur Respir J. 2002;20:1003-1009.

57. Colt HG. Thoracoscopy. A prospective study of safety and outcome. Chest. 1995;108:324-329.

58. LeRoux BT. Bronchial carcinoma with pleural effusion. S Afr Med J. 1968;42:865-866

59. Heaton RW, Roberts CM. The role of fibreoptic bronchoscopy in the investigation of pleural effusion. Postgrad Med J. 1988;64:581-582.

60. Berger HW, Mejia E. Tuberculous pleurisy. Chest. 1973;63:88-92.

61. Yam LT. Diagnostic significance of lymphocytes in pleural effusions. Ann Intern Med. 1967;66:972-982.

62. Hurwitz S, Leiman G, Shapiro C. Mesothelial cells in pleural fluid: TB or not TB? S Afr Med J. 1980;57:937-939.

63. Jones D, Lieb T, Narita M, Hollender ES, Pitchenik AE, Ashkin D. Mesothelial cells in tuberculous effusions of HIV-infected patients. Chest. 2000;117:289-291.

64. Heyderman RS, Makunike R, Muza T, et al. Pleural tuberculosis in Harare, Zimbabwe: the relationship between human immunodeficiency virus, CD4 lymphocyte count, granuloma formation and disseminated disease. Trop Med Int Health. 1998;3:14-20. 
65. Valdes L, Alvarez D, San Jose E, et al. Tuberculous pleurisy: a study of 254 patients. Arch Intern Med. 1998;158:2017-2021.

66. Levine H, Metzger W, Lacera D, Kay L. Diagnosis of tuberculous pleurisy by culture of pleural biopsy specimen. Arch Intern Med. 1970;126:269-271.

67. Valdes L, San Jose ME, Pose A, et al. Diagnosing tuberculous pleural effusion using clinical data and pleural fluid analysis. A study of patients less than 40 years-old in an area with a high incidence of tuberculosis. Respir Med. 2010;104:1211-1207.

68. Piras MA, Gakis C, Budroni M, Andreoni G. Adenosine deaminase activity in pleural effusions: an aid to differential diagnosis. $\mathrm{Br} \mathrm{Med} J$ 1978;2:1751-1752.

69. Burgess LJ, Maritz FJ, Le Roux I, Taljaard JJ. Use of adenosine deaminase as a diagnostic tool for tuberculous pleurisy. Thorax. 1995;50:672-674.

70. Valdes L, Jose ES, Alvarez D, Valle JM. Adenosine deaminase isoenzyme analysis in pleural effusions: diagnostic role and relevance to the origin of increased ADA in tuberculous pleurisy. Eur Resp J. 1996;9:747-751.

71. Zemlin AE, Burgess LJ, Carstens ME. The diagnostic utility of adenosine deaminase isoenzymes in tuberculous pleural effusions. Int JTuberc Lung Dis. 2009;13:214-220.

72. Hsu WH, Chiana CD, Huang PL. Diagnostic value of pleural adenosine deaminase in tuberculous effusions of immunocompromised hosts. J Formos Med Assoc. 1993;92:668-670.

73. Titarenko OT, D'iakova ME, Perova TL, D'iakova AI, Popov MIu. Informative value of adenosine deaminase and 2-deoxyadenosine deaminase in the diagnosis of tuberculous pleurisy. Klin Lab Diagn. 2002;5:11-14. Russian.

74. Bartlett JG, Finegold SM. Anaerobic infections of the lung and pleural space. Am Rev Respir Dis. 1974;110:56-77.

75. Light RW. Parapneumonic effusions and empyema. Proc Am Thorac Soc. 2006;3:75-80.

76. Muduly DK, Deo SVS, Subi TS, Kallianpur AA, Shukla NK. An update in the management of malignant pleural effusion. Indian J Palliat Care. 2011;17:98-103.

77. Awasthi A, Gupta N, Srinivasan R, Nijhawan R, Rajwanshi A. Cytopathological spectrum of unusual malignant pleural effusions at a tertiary care centre in north India. Cytopathology. 2007;18:28-32.

78. Lee YC, Light RW, Musk AW. Management of malignant pleural mesothelioma: a critical review. Curr Opin Pulm Med. 2000;6:267-274.

79. Rice TW, Rodriguez RM, Barnette R, Light RW. Prevalence and characteristics of pleural effusions in superior vena cava syndrome. Respirology. 2006;11:299-305.

80. Qureshi NR, Gleeson FV. Imaging of pleural disease. Clin Chest Med. 2006;27:193-213.

81. Leung AN, Muller NL, Miller RR. CT in differential diagnosis of diffuse pleural disease. Am J Roentgenol. 1990;154:487-492.

82. Yilmaz U, Polat G, Sachin N, Soy O, Gulay U. CT in differential diagnosis of benign and malignant pleural disease. Monaldi Arch Chest Dis. 2005;63:17-22.

83. Traill ZC, Davies RJ, Gleeson FV. Thoracic computed tomography in patients with suspected malignant pleural effusions. Clin Radiol. 2001;56:193-196.

84. Maskell NA, Gleeson FV, Davis RJ. Standard pleural biopsy versus CT-guided cutting needle biopsy for diagnosis of malignant disease in pleural effusions: a randomized controlled trial. Lancet. 2003;361:1326-1330.

85. Lee YC, Light RW. Management of malignant pleural effusions. Respirology. 2004;9:148-156.

86. Sahn SA. Management of malignant pleural effusions. Monaldi Arch Chest Dis. 2001;56:394-399.

87. Groth G, Gatzemeier U, Haussingen K, et al. Intrapleural palliative treatment of malignant pleural effusions with mitoxantrone versus placebo (pleural tube alone). Ann Oncol. 1991;2:213-215.

88. Antunes G, Neville E, Duffy J, Ali N; BTS Pleural Disease Group, a subcommittee of the BTS Standards of Care Committee. BTS guidelines for the management of malignant pleural effusions. Thorax 2003;58:ii29-ii38.
89. Whitaker D. The cytology of malignant mesothelioma. Cytopathology. 2000;11:139-151.

90. Brown RW, Clark GM, Tandon AK, Allred DC. Multiple-marker immunohistochemical phenotypes distinguishing malignant pleural mesothelioma from pulmonary adenocarcinoma. Hum Pathol. 1993;24:347-354.

91. Helmers R, Galvin J, Hunninghake CW. Pulmonary manifestations associated with rheumatoid arthritis. Chest. 1991;100:235-238.

92. Walker WC, Wright V. Pulmonary lesions and rheumatoid arthritis. Medicine. 1968;47:501-520.

93. Allen JS, Donahue DM, Garrity JM. Rheumatoid pleural effusion in the absence of arthritic disease. Ann Thorac Surg. 2005;80:1519-1521.

94. Lillington GA, Carr DT, Mayne JG. Pleurisy with effusion in rheumatoid arthritis with reference to the low concentration of glucose in pleural fluid. Am Rev Respir Dis. 1962;88:345-350.

95. Dodson WH, Hollingsworth JW. Pleural effusion in rheumatoid arthritis: Impaired transport of glucose. N Engl J Med. 1966;275:1337-1342.

96. Sahn SA, Kaplan RL, Maulitz RM, Good JT Jr. Rheumatoid pleurisy: observation on the development of low pleural fluid $\mathrm{pH}$ and glucose level. Am J Resp Crit Care Med. 1980;140:1237-1238.

97. Haput HM, Moore WG, Huthin GM. The lung in SLE. Am J Med. 1981;71:791-798.

98. Good JT Jr, King TE, Antony VB, Sahn SA. Lupus pleuritis. Clinical features and pleural fluid characteristics with special reference to pleural fluid anti-nuclear antibody. Chest. 1983;84:714-718.

99. Ibarra-Perez C. Thoracic complications of amebic abscess of the liver: report of 501 cases. Chest. 1981;79:672-676.

100. Cameron EWJ. The treatment of pleuropulmonary amebiasis with metronidazole. Chest. 1978;73:647-650.

101. Vergese M, Eggleston FC, Handa AK, Singh CM. Management of thoracic amebiasis. J Thorac Cardiovasc Surg. 1979;78:757-760.

102. Rasaretnam R, Paul ATS, Yoganathan M. Pleural empyema due to ruptured amebic liver absecess. Br J Surg. 1974;61:713-715.

103. Shrinivasan B, Mohite PN, Thingnam SK. Extrapulmonary intrapleural hydatid cysts - rare variant of uncommon disease. Indian $J$ Thorac Cardiovasc Surg. 2010;26:247-250.

104. Ozvaran MK, Ersoy Y, Uskul B, et al. Pleural complications of pulmonary hydatid disease. Respirology. 2004;9:115-119.

105. Thameur H, Chenik S, Abdelmoulah S, et al. Thoracic hydatidosis. A review of 1619 cases. Rev Pneumol Clin. 2000;56:7-15.

106. Kaye MD. Pleuropulmonary complications of pancreatitis. Thorax. 1968;23:297-305.

107. Anderson WJ, Skinner DB, Zuidema GD, Cameron DL. Chronic pancreatic pleural effusions. Surg Gynecol Obstet. 1973;137:827-830.

108. Tabor E, Russell RP, Gerety RJ, Barker LF, Hillis WD, Jackson DR. Hepatitis B surface antigen and e antigen in pleural effusion: A case report. Gastroenterology. 1977;73:1157-1159.

109. Sahn SA. State of the art: the pleura. Am Rev Respir Dis. 1988;138:184-234.

110. DeMeester T. The pleura. In: Spenser E, editor. Surgery of the Chest. 4th ed. Philadelphia, PA: WB Saunders; 1983.

111. Bessone L, Ferguson T, Burford T. Chylothorax: a collective review. Ann Thorac Surg. 1971;12:527-550.

112. Hamm H, Pfalzer B, Fabel H. Lipoprotein analysis in a chyliform pleural effusion: implications for pathogenesis and diagnosis. Respiration. 1991;58:294-300.

113. Ferguson G. Cholesterol pleural effusion in rheumatoid lung disease. Thorax. 1966;21:577-582.

114. Meigs JV, Cass JW. Fibroma of the ovary with ascites and hydrothorax. Am J Obstet Gynecol. 1937;33:249-267.

115. Samanth KK, Black WC III. Benign ovarian stromal tumors associated with free peritoneal fluid. Am J Obstet Gynecol. 1970;107: $538-545$.

116. Bachman AL, Macken K. Pleural effusions following supervoltage radiation for breast carcinoma. Radiology. 1959;72:699-709.

117. Farber JE, Lincoln NS. The unexpandable lung. Statement of the problem. Am Rev Tuberc. 1939;40:704-709. 
118. Mitrouska I, Bouros D. The trans-exudative pleural effusions. Chest. 2002;122:1503-1505.

119. Zhou Q, Ye ZJ, Su Y, Zhang JC, Shi HZ. Diagnostic value of N-terminal pro-brain natriuretic peptide for pleural effusion due to heart failure: a meta-analysis. Heart. 2010;96:1207-1211.

120. Albert WM, Salem AJ, Solomon DA, Boyce G. Hepatichydrothorax cause and management. Arch Intern Med. 1991;151:2383-2388.

121. Chen A, Yat-Sen H, Yen-Chang T, Hung-Shang T, TungChao C. Diaphragmatic defect as a cause of massive hydrothorax in cirrhosis of the liver. J Clin Gastroenterol. 1988;10:663-666.

122. Kakizaki S, Katakai K, Yoshinaga T, et al. Hepatic hydrothorax in the absence of ascites. Liver. 1998;18:216-220.

123. Gurung P, Goldblatt M, Huggins JT, Doelken P, Nietert PJ, Sahn SA. Pleural fluid analysis and radiographic, sonographic, and echocardiographic characteristics of hepatic hydrothorax. Chest. 2011;140:448-453.

124. Rudnick MR, Coyle JF, Beck LH, McCurdy DK. Acute massive hydrothorax complicating dialysis. Report of 2 cases and a review of the literature. Clin Nephrol. 1979;12:38-44.

125. Adam WR, Arkles LB, Gilli G, Meagher E, Thomas GW. Hydrothorax with peritoneal dialysis: radionucleotide detection of a pleuroperitoneal connection. Aust N Z J Med. 1980;10:330-332.

126. Stark DD, Shanes JG, Baron RL, Koch DD. Biochemical features of urinothorax. Arch Intern Med. 1982;142:1509-1511.

127. Cavina C, Vicni G. Radiological aspects of pleural effusions in medical nephropathy in children. Ann Radiol Diagn (Bologna). 1958;31:163202. Italian.

128. Ito T, Engle MA, Goldberg HP. Postpericardiotomy syndrome following surgery for non-rheumatic heart disease. Circulation. 1958;17:549-556.

129. Dressler W. A post-myocardial infarction syndrome; preliminary report of a complication resembling idiopathic, recurrent, benign pericarditis. JAMA. 1956;160:1379-1383.

130. Sklaroff HJ. Post-pulmonary infarction syndrome. Am Heart J. 1979;98:722-726.

131. Bajaj BPS, Evans KE, Thomas P. Postpericardiotomy syndrome following temporary and permanent transvenous pacing. Postgrad Med J. 1999;75:357-358.

132. Loughlin V, Murphy A, Russell C. The post-pericardiotomy syndrome and penetrating injury of the chest. Injury. 1987;18:412-414.

133. Khan AH. The postcardiac injury syndromes. Clin Cardiol. 1992;15: 67-72.

134. Cohen M, Sahn SA. Resolution of pleural effusions. Chest. 2001;119:1547-1562.

135. Robinson BWS, Musk AW. Benign asbestos pleural effusion: diagnosis and course. Thorax. 1981;36:896-900.

136. Chertow BS, Kadzielawa R, Burger AJ. Benign pleural effusions in long-standing diabetes mellitus. Chest. 1991;99:1108-1111.

137. Sachdev Y, Hall R. Effusions into body cavities in hypothyroidism. Lancet. 1975;1:564-566.

138. Wier-Kronish JP, Broaddus VC, Albertine KH, Gropper, Mathway MA, Staub NC. Relationship of pleural effusions to increased permeability pulmonary edema in anesthetized sheep. J Clin Invest. 1988;82: 1422-1429.

139. Lai-Fook SJ. Mechanics of the pleural space: fundamental concepts. Lung. 1987;165:249-267.

Open Access Emergency Medicine

\section{Publish your work in this journal}

Open Access Emergency Medicine is an international, peer-reviewed, open access journal publishing original research, reports, editorials, reviews and commentaries on all aspects of emergency medicine. The manuscript management system is completely online and includes a very quick and fair peer-review system, which is all easy to use.
140. Heffner JE, Sahn SA. Pleural disease in pregnancy. Clin Chest Med. 1992;13:667-678.

141. Stark P, Pollack MS. Pleural effusions in the postpartum period. Radiology. 1986;26:471-475.

142. Engel ME, Matchaba PT, Volmin J. Corticosteroids for tuberculous pleurisy. Cochrane Database Syst Rev. 2007;4:CD001876.

143. Dhebri AR, Ferran N. Nonsurgical management of pancreaticopleural fistula. J Pancreas. 2005;51:1-6.

144. Porcel JM, Light RW. Diagnostic approach to pleural effusion in adults. Am Fam Physician. 2006;73:1211-1220.

145. Light RW. Diagnostic principles in pleural disease. Eur Respir J. 1997;10:476-481.

146. Antony VB, Loddenkemper R, Astoul P, Boutin C, Goldstraw P, Hott J. Management of malignant pleural effusions. Eur Respir J. 2001;18:402-419.

147. Walker-Renard PB, Vaughan LM, Sahn SA. Chemical pleurodesis for malignant pleural effusions. Ann Intern Med. 1994;120:56-64.

148. Cardillo G, Facciolo F, Carbone L, Regal M, Corzani F, Ricci A. Long-term follow-up of video-assisted talc pleurodesis in malignant recurrent pleural effusions. Eur J Cardiothorac Surg. 2002;21: 302-305.

149. Trotter D, Aly A, Siu L, Knight S. Video-assisted thoracoscopic pleurodesis for malignant effusion: an Australian teaching hospital's experience. Heart Lung Circ. 2005;14:93-97.

150. Colice GL, Curtis A, Deslauriers J, et al. Medical and surgical treatment of parapneumonic effusions: an evidence based guideline. Chest. 2000;118:1158-1171.

151. Mulvey RB. The effect of pleural fluid on the diaphragm. Radiology. 1965;84:1080-1086.

152. Estenne M, Yerrault JC, de Troyer A. Mechanism of relief of dyspnea after thoracocentesis in patients with large pleural effusions. Am J Med. 1983;74:813-819.

153. Perpina M, Benlloch E, Marco V, Abad F, Nauffal D. Effect of thoracocentesis on pulmonary gas exchange. Thorax. 1983;38:747-750.

154. Matthews HR, McGuigan JA. Closed chest drainage without an underwater seal. Thorax. 1988;41:804P.

155. Joshi JM. Intercostal tube drainage of pleura: Urosac as a chest drainage bag. J Assoc Physicians India. 1996;44:381-382.

156. Sudduth C, Sahn SA. Pleurodesis for nonmalignant pleural effusions: recommendations. Chest. 1992;102:1855-1860.

157. Vargas FS, Milanez JRC, Filomeno LTB, Fernandez A, Jatene A, Light RW. Intrapleural talc for the prevention of recurrence in benign or undiagnosed pleural effusions. Chest. 1994;106:1771-1775.

158. Molnar TF. Current surgical treatment of thoracic empyema in adults. Eur J Cardiothorac Surg. 2007;32:422-430.

159. Neff CC, Van Sonnenberg E, Lawson DW, Patten AS. CT follow up of empyema: pleural peels resolve after percutaneous catheter drainage. Radiology. 1990;176:195-197.

160. Jain SK, Gupta P, Swaroo K. Conservative management of BPF. Ind J Chest Dis. 1975;17:79-84.

161. Petty TL, Filley GF, Mitchell RS. Objective functional improvement by decortication after 20 years of artificial pneumothorax for pulmonary tuberculosis. Am Rev Respir Dis. 1961;84:572-578.

\section{Dovepress}

Visit http://www.dovepress.com/testimonials.php to read real quotes from published authors. 